\title{
THE MACRO EFFECTS OF UNEMPLOYMENT BENEFIT EXTENSIONS: A MEASUREMENT ERROR APPROACH*
}

\author{
Gabriel Chodorow-Reich \\ JoHN COGLIANESE \\ LOUKAS KARABARBOUNIS
}

\begin{abstract}
By how much does an extension of unemployment benefits affect macroeconomic outcomes such as unemployment? Answering this question is challenging because U.S. law extends benefits for states experiencing high unemployment. We use data revisions to decompose the variation in the duration of benefits into the part coming from actual differences in economic conditions and the part coming from measurement error in the real-time data used to determine benefit extensions. Using only the variation coming from measurement error, we find that benefit extensions have a limited influence on state-level macroeconomic outcomes. We apply our estimates to the increase in the duration of benefits during the Great Recession and find that they increased the unemployment rate by at most 0.3 percentage point. JEL Codes: E24, E62, J64, J65.
\end{abstract}

\section{INTRODUCTION}

Responding to the increase in unemployment during the Great Recession, the potential duration of unemployment insurance (UI) benefits in the United States increased from 26 weeks to up to 99 weeks. Recent studies have found mixed effects of these benefit extensions on individual outcomes (Rothstein 2011; Farber and Valletta 2015; Johnston and Mas forthcoming). The effect on macroeconomic outcomes has been even more controversial. According to one view, by making unemployment relatively more attractive to the jobless, the extension of benefits contributed substantially to the slow recovery of the labor market (Barro 2010; Hagedorn et al. 2015). Others have emphasized the

\footnotetext{
${ }^{*}$ We are grateful to Robert Barro, Larry Katz, Andi Mueller, Emi Nakamura, Matt Notowidigdo, six anonymous referees, and participants in seminars and conferences for helpful comments. We thank Claudia Macaluso and Johnny Tang for excellent research assistance, Thomas Stengle of the Department of Labor for help in understanding the unemployment insurance laws, and Bradley Jensen of the Bureau of Labor Statistics for help in understanding the process for constructing state unemployment rates. Karabarbounis thanks the Alfred P. Sloan Foundation for generous financial support. The views expressed herein are those of the authors and not necessarily those of the Federal Reserve Bank of Minneapolis, Board of Governors, or the Federal Reserve System.

(C) The Author(s) 2018. Published by Oxford University Press on behalf of the President and Fellows of Harvard College. All rights reserved. For Permissions, please email: journals.permissions@oup.com

The Quarterly Journal of Economics (2019), 227-279. doi:10.1093/qje/qjy018.

Advance Access publication on August 20, 2018.
} 
potential stimulus effects of increasing transfers to unemployed individuals (Summers 2010; Congressional Budget Office 2012). Distinguishing between these possibilities has important implications for the design of UI policy and for economists' understanding of labor markets.

Quantifying the effects of UI benefit extensions on macroeconomic outcomes is challenging. Federal law links actual benefit extensions in a state directly to state-level macroeconomic conditions. This policy rule mechanically generates a positive correlation between unemployment and benefit extensions, complicating the identification of any direct effect that benefit extensions may have on macroeconomic outcomes.

To shed light on this policy debate, we propose a novel empirical design that exploits state variation in benefit extensions caused by measurement error. Our results are inconsistent with large effects of benefit extensions on state-level macroeconomic aggregates, including unemployment, employment, vacancies, and worker earnings. Instead, we find that the extension of benefits has only a limited influence on macroeconomic outcomes.

Our empirical approach starts from the observation that at the state level, the duration of UI benefits depends on the unemployment rate as estimated in real time. However, real-time data provide a noisy signal of the true economic fundamentals. It follows that two states differ in the duration of their UI benefits either because of differences in fundamentals or because of measurement error. We use subsequent revisions of the unemployment rate to separate the fundamentals from the measurement error. We then use the measurement error component of UI benefit extensions to identify the effects of benefit extensions on state-level macroeconomic aggregates. Effectively, our strategy exploits the randomness in the duration of benefits with respect to economic fundamentals caused by measurement error in the fundamentals.

Table I uses the example of Louisiana and Wisconsin in April 2013 to illustrate our approach. Under the 2008 emergency compensation program, the duration of benefits in a state increased by 14 additional weeks if a moving average of the state's unemployment rate exceeded $6 \%$. The unemployment rate measured in real time in Louisiana was 5.9\% whereas that in Wisconsin was $6.9 \%$, resulting in an additional 14 weeks of potential benefits in Wisconsin relative to Louisiana. However, data revised as of 2015 show that both states actually had the same unemployment rate 
TABLE I

APRIL 2013 EXAMPLE

\begin{tabular}{llcc}
\hline \hline & & Louisiana & Wisconsin \\
\hline Real-time data & Unemployment rate (moving average) & $5.9 \%$ & $6.9 \%$ \\
& duration of benefit extensions & 14 weeks & 28 weeks \\
Revised data & Unemployment rate (moving average) & $6.9 \%$ & $6.9 \%$ \\
& duration of benefit extensions & 28 weeks & 28 weeks \\
& UI error & -14 weeks & 0 weeks \\
\hline \hline
\end{tabular}

of $6.9 \%$. According to the revised data, both states should have qualified for the additional 14 weeks. We refer to the 14 weeks that Louisiana did not receive as a "UI error." This error reflects mismeasurment of the economic fundamentals rather than differences in fundamentals between the states and therefore provides variation to identify the effects of UI benefit extensions on state aggregates. The actual unemployment rate (from the revised data as of 2015) evolved very similarly following the UI error, declining by roughly 0.2 percentage point between April and June 2013 in both states. Our empirical exercise amounts to asking whether this apparently limited influence of extending benefits on unemployment generalizes to a larger sample.

We begin our analysis by discussing relevant institutional details of the UI system, the measurement of real-time and revised state unemployment rates, and the UI errors that arise because of differences between real-time and revised data. The Bureau of Labor Statistics (BLS) constructs state unemployment rates by combining a number of state-level data sources using a statespace model. Revisions to state unemployment rates occur due to revisions to the input data, the use of the full time series of available data in the state-space estimation at the time of the revision, and the introduction of technical improvements in the statistical model itself. Of these, the technical improvements account for the largest share of the variation in the measurement error in the unemployment rate. The unemployment rate measurement error gives rise to more than 600 state-month cases between 1996 and 2015 in which, as in the example of Louisiana and Wisconsin in April 2013, the duration of benefits using the revised data differs from the actual duration of benefits. Almost all of these UI errors occur during the Great Recession. This concentration reflects the additional tiers of benefits duration created by the 2008 
emergency compensation program and the fact that most states experienced unemployment rates high enough for measurement errors to affect their eligibility for extended benefits. Once a UI error occurs, it takes on average nearly four months to revert to zero.

We estimate impulse responses of state-level labor market variables to an unexpected innovation in the UI error. Our identifying assumptions are that innovations in the UI error occur randomly with respect to the true economic fundamentals and that the revised unemployment rate measures the true economic fundamentals in the state. Our main result is that innovations in the UI error have negligible effects on state-level unemployment, employment, vacancies, and worker earnings. In the baseline specification, a one-month increase in the maximum potential duration of benefits generates at most a 0.02 percentage point increase in the state unemployment rate. Crucially, a positive UI error innovation raises the fraction of the unemployed who receive UI benefits by a statistically significant and economically reasonable magnitude, with the additional recipients being in the tiers affected by the error. Therefore, our results do not reflect a failure of UI errors to lead to a larger fraction of the unemployed receiving benefits. They simply reflect the small macroeconomic effects of an increase in UI eligibility and receipt.

These impulse responses answer the question of what would happen if a state increased the duration of unemployment benefits around the neighborhood of a typical UI error, or by about three months after a state has already extended benefits by nearly one year. To assess the informativeness of these estimates for other types of policies, we examine the heterogeneity of responses with respect to the initial level of benefit duration and the persistence of the UI error. The responses of labor market variables such as unemployment and vacancies do not vary along either dimension. Therefore, a linear extrapolation of our estimates provides a reasonable guide to the macroeconomic effects of longer extensions. Taking the upper bound of our preferred specification, we find that extending benefits from 26 to 99 weeks increases the unemployment rate by at most 0.3 percentage point.

We show the robustness of our results to the inclusion of a number of controls into the baseline specification and to alternative specifications. Most important, a concern with using revisions in the unemployment rate to construct UI errors is that the incorporation of the full time series of data in the revision process 
makes the unemployment rate revision in month $t$ partly dependent on realizations of variables after month $t$. To make sure this aspect of the revision process does not affect our results, we add to our regression controls for linear and nonlinear functions of the unemployment rate measurement error. The responses of labor market variables remain similar to our baseline estimates, reflecting the fact that this aspect of the revision process contributes very little to the variation in the unemployment rate measurement error. Furthermore, we develop an alternative series of UI errors using sampling error in the Current Population Survey (CPS). We infer the sampling error from the difference between a measure of the population eligible for regular benefits in the CPS and administrative data on UI receipt. UI errors constructed using only this more restrictive source of measurement error do not depend at all on realizations of variables at future dates. We continue to find a limited effect of unemployment benefit extensions on labor market outcomes using this approach.

Finally, we derive a bound for the consistency of our estimator when the revised data still contain measurement error. Intuitively the bound depends on the measurement error in the revised data relative to that in the real-time data. We show that the macroeconomic effects of benefit extensions are small as long as the revised data measure true economic conditions at least as well as the realtime data. We provide empirical support for this condition from horse-race regressions in which measures of consumer spending and survey attitudes and beliefs load on the revised but not on the real-time unemployment rate.

In the last part of the article we complement our empirical results by analyzing a DMP model (Diamond 1982; Mortensen and Pissarides 1994) augmented with a UI policy. The model provides an alternative approach to considering larger extensions in the duration of benefits and allows anticipation effects by workers and firms to differ according to whether a benefit extension is caused by a transitory UI error or by a persistent increase in unemployment that triggers the extension. As is well known in the literature, the effect of UI policy on macroeconomic outcomes depends crucially on the level of the opportunity cost of employment. We show that with a relatively low level of the opportunity cost of employment, such as the one estimated in Chodorow-Reich and Karabarbounis (2016), a one-month UI error innovation leads to a less than 0.02 percentage point increase in the unemployment rate, a magnitude similar to our empirical 
estimates. To mimic the U.S. experience in the aftermath of the Great Recession, we subject the model to a sequence of large negative shocks that increase unemployment from below $6 \%$ to roughly $10 \%$ and increase the duration of benefits from 6 months to 20 months. Removing benefit extensions leads to a decline in the unemployment rate by at most 0.3 percentage point in the model. Thus, a linear extrapolation of the empirical results and the model exercise suggest a small response of unemployment to the extension of benefits around the Great Recession.

The economic literature on the effects of benefit extensions has followed two related lines of inquiry. Motivated in part by a partial equilibrium optimal taxation result linking the optimal provision of UI to individual search behavior (Baily 1978; Chetty 2006), a microeconomic literature has studied how various aspects of UI policy affect individual labor supply (for a survey, see Krueger and Meyer 2002). Studies that find a small effect of benefit extensions following the Great Recession on individual job-finding rates and unemployment duration include Rothstein (2011) and Farber and Valletta (2015), while Johnston and Mas (forthcoming) find somewhat larger effects in a study of a single benefit cut in Missouri in $2011 .^{1}$

The macroeconomic effects of UI benefits concern their effect on aggregate unemployment. ${ }^{2}$ Economic theory does not provide a one-to-one mapping between the magnitude of the microeconomic and macroeconomic effects. For example, in a standard DMP model with exogenous job search effort and Nash bargaining, an increase in UI benefits raises workers' outside options, putting an upward pressure on wages and depressing firm vacancy creation. Exogenous search effort implies a zero microeconomic effect, but the decline in total vacancies generates a rise in total unemployment, that is, a nonzero macroeconomic effect (Hagedorn et al. 2015). Alternatively, in models with job rationing, large

1. Schmieder, von Wachter, and Bender (2012) and Kroft and Notowidigdo (2016) show that the effect of UI benefit extensions on unemployment duration becomes smaller during recessions.

2. Our estimates of the macroeconomic effects are particularly informative for general equilibrium models with UI policy. See Hansen and Imrohoroglu (1992), Krusell, Mukoyama, and Sahin (2010), and Nakajima (2012) for earlier general equilibrium analyses of unemployment insurance policy. Landais, Michaillat, and Saez (2018) and Kekre (2016) extend the Baily-Chetty partial equilibrium optimal UI formula to a general equilibrium setting and show how it depends on the macroeconomic effects of benefit extensions. 
microeconomic effects could be consistent with small macroeconomic effects if the job-finding rate of UI recipients falls but that of nonrecipients rises (Levine 1993; Lalive, Landais, and Zweimüller 2015; Landais, Michaillat, and Saez 2018). Crepon et al. (2013) provide experimental evidence that such displacement effects occur in the related setting of job placement assistance programs.

A number of papers starting with Hagedorn et al. (2015, HKMM) and Hagedorn, Manovskii, and Mitman (2015, HMM) use a county border discontinuity design to estimate the macroeconomic effects of UI benefit extensions. Different from our results, HKMM and HMM find a large positive effect of benefit extensions on unemployment. However, the subsequent literature has challenged these findings. Hall (2013) first pointed out problems that arise from the imputation of the unemployment rate at the county level and raised conceptual questions about the identification strategy in HKMM. Amaral and Ice (2014) argue the results in HKMM are sensitive to changes in the data sources and the specification, points developed further in Boone et al. (2016) and Dieterle, Bartalotti, and Brummet (2016). Boone et al. (2016) find near zero effects of UI extensions on employment using a county border design and a more flexible empirical model. They further show that using newer vintages of the unemployment data substantially reduces or eliminates the positive effect of benefit extensions on unemployment found in HKMM and HMM. ${ }^{3}$ Dieterle, Bartalotti, and Brummet (2016) point out that shocks triggering UI extensions in one state may not affect neighboring counties similarly because population does not concentrate at the border. They refine the border-county-pair strategy by controlling for polynomials in the distance to the border and find a small response of unemployment to benefit extensions. Finally, both Dieterle, Bartalotti, and Brummet (2016) and Marinescu (2017) cite job search spillovers across counties to question the appropriateness of a border design to study UI extensions.

Other papers using cross-state variation find mixed macroeconomic effects. Johnston and Mas (forthcoming) use a sudden

3. For example, Boone et al. (2016) find that HMM's estimated effect falls by three-quarters and becomes statistically indistinguishable from zero using the newer data. They also forcefully question the assumptions underlying the quasiforward differencing procedure used in HKMM. As they point out, if the true effect of UI extensions were to cause unemployment to slightly decrease, applying the quasi-differencing procedure would nonetheless cause a researcher to conclude benefit extensions increase unemployment. 
change in benefits in Missouri to estimate the microeconomic and macroeconomic effects. They estimate macroeconomic effects of similar magnitude to the microeconomic effects, but their estimate of the macroeconomic effect depends on a differencein-differences research design with Missouri the only treated observation. Marinescu (2017) uses data from a large job board and documents an insignificant effect of benefit duration on vacancies. Relative to this literature, ours is the first article to use quasi-experimental cross-state variation to estimate the macroeconomic effect of UI extensions on unemployment.

\section{Unemployment InsURANCE IN the United StateS}

The maximum number of weeks of UI benefits available in the United States varies across states and over time. Regular benefits in most states provide 26 weeks of compensation, with a range between 13 and 30 weeks. The existence of regular UI benefits does not depend on economic conditions in the state. Extended benefits (EB) and emergency compensation provide additional weeks of benefits during periods of high unemployment in a state. The EB program has operated since 1970 and is 50\% federally funded except for the period 2009-2013 when it became fully federally funded. Emergency compensation programs are authorized and financed on an ad hoc basis by the federal government. In our sample (1996-2015), the Temporary Emergency Unemployment Compensation (TEUC) program operated between March 2002 and December 2003 and the Emergency Unemployment Compensation (EUC) program operated between July 2008 and December 2013. We refer to the combination of EB and emergency compensation as UI benefit extensions.

Whether a state qualifies for benefit extensions typically depends on the unemployment rate exceeding some threshold. Two measures of unemployment arise in the laws governing these extensions. The insured unemployment rate (IUR) is the ratio of recipients of regular benefits to employees covered by the UI system. The total unemployment rate (TUR) is the ratio of the total number of individuals satisfying the official definition of not working and on layoff or actively searching for work to the total labor force. To avoid high frequency movements in the available benefit extensions, the IUR and the TUR enter as three-month moving averages into the trigger formulas determining extensions. A trigger may also contain a lookback provision, which requires that the 
indicator exceed its value during the same set of months in prior years. Appendix Table A.1 lists the full set of benefit extension programs, tiers, and triggers in operation during our sample.

Not every unemployed individual qualifies for regular benefits, with eligibility determined by reason for separation from previous employer, earnings over the previous year, and search effort. An individual becomes eligible to receive benefits under EB or an emergency program only after qualifying for and exhausting entitlement under regular benefits. Any individuals who have exhausted eligibility under all previous tiers become immediately eligible to receive benefits when their state triggers onto a new tier. Conversely, as soon as a state triggers off a tier all individuals lose eligibility immediately regardless of whether they had begun to collect benefits on that tier.

\section{EMPIRICAL Design}

We organize the discussion of our empirical methodology around a linear relationship between a labor market variable $y_{s, t}$ observed in state $s$ at date $t$ and the maximum duration of unemployment benefit receipt in the state $T_{s, t}^{*}$ :

$$
y_{s, t}=b(0) T_{s, t}^{*}+\sum_{j=-\infty}^{-1} b(-j) T_{s, t+j}^{*}+\sum_{j=1}^{\infty} b(-j) \mathbb{E}_{t} T_{s, t+j}^{*}+\eta_{s, t},
$$

where $\eta_{s, t}$ includes all other determinants of the labor market variable. We allow leads and lags of the duration of UI benefits to affect the dependent variable because labor market outcomes may depend not only on contemporaneous but also on past and expected future benefit duration. We denote by $\mathbb{E}_{t}$ the expectation operator using information available as of period $t$.

Two main challenges arise in estimating the causal effect of extending benefits on state-level labor market outcomes. First, the extension of benefits depends on labor market outcomes, such as the state unemployment rate, inducing a correlation between $\eta_{s, t}$ and $T_{s, t}^{*}$. Section III.A shows how to separate the benefit duration $T_{s, t}^{*}$ into the part that depends on true economic fundamentals and the part that depends on measurement error in the fundamentals in order to address this identification challenge. Second, the duration of benefits $T_{s, t}^{*}$ is autocorrelated over time. Section III.B explains how we extract the unexpected 
component of the measurement error part in order to address this issue of serial correlation in the duration of benefits. Section III.C combines these elements and presents our empirical specification.

\section{III.A. Endogeneity of Benefit Duration}

The key idea of our approach is to use the variation in the duration of benefits caused only by measurement error in state-level labor market outcomes. To implement this idea, we decompose the benefit duration $T_{s, t}^{*}$ into the part that depends on true economic fundamentals in the state, $T_{s, t}$, and the part that depends on measurement error in the fundamentals, $\hat{T}_{s, t}$. Let $f_{s, t}$.) be the UI law that maps a history of unemployment rates in a state $s$ into the maximum duration of UI benefit extensions in the state. The time subscript $t$ on the function indicates that the mapping can change due to temporary legislation, such as an emergency compensation program. As described in Section II, whether a state extends its duration of benefits depends on the most recently reported or "real-time" estimate of the state-level unemployment rate:

$$
T_{s, t}^{*}=f_{s, t}\left(u_{s, t-1}^{*}\right),
$$

where $u_{s, t-1}^{*}$ denotes the real-time unemployment rate reported in month $t$ for the latest available month, $t-1 .^{4}$

The reported unemployment rate in real time, $u_{s, t}^{*}$, may deviate from the true unemployment rate, $u_{s, t}$, because of

4. For expositional reasons, we simplify a few details in writing monthly UI duration as a function of the previous month's unemployment rate. The actual determination of UI benefit extensions eligibility occurs weekly and is based on unemployment rate data available at the start of the week. The BLS typically releases the real-time state total unemployment rate data for month $t-1$ around the 20th day of month $t$. Therefore, for the first weeks of month $t$ the most recent real-time unemployment rate which enters into the eligibility determination is for month $t-2$ while for the last weeks the most recent unemployment rate affecting eligibility is for month $t-1$. We aggregate in the text to a monthly frequency and capture the reporting lag for the real-time data by writing UI benefits in month $t$ as a function of the unemployment rate in month $t-1$. Next, benefit duration typically depends on a 3-month moving average of unemployment rates and may also depend on a "lookback" to the unemployment rate 12 and 24 months before, so that further lags of the unemployment rates also enter into the eligibility determination. Third, duration also depends on the insured unemployment rate, although this trigger binds very rarely in our sample. Although we appropriately take into account all of these details in our implementation, they do not affect the general econometric approach so we omit them in the main text for clarity. 
measurement error, denoted by $\hat{u}_{s, t}=u_{s, t}^{*}-u_{s, t}$. Our empirical strategy exploits variation in this measurement error to extract the component of benefit extensions which is uncorrelated with state economic conditions. More formally, we first define a hypothetical duration of benefit extensions, $T_{s, t}$, based on the true unemployment rate $u_{s, t}$ and the same function $f_{s, t}($.$) that appears$ in equation (2):

$$
T_{s, t}=f_{s, t}\left(u_{s, t-1}\right) \text {. }
$$

We then define the UI error $\hat{T}_{s, t}$ from the relationship:

$$
T_{s, t}^{*}=T_{s, t}+\hat{T}_{s, t} .
$$

Equation (4) shows that variation in the actual duration of benefit extensions $T_{s, t}^{*}$ comes from the component $T_{s, t}$, which depends on the true economic fundamentals, and from the component $\hat{T}_{s, t}$, which reflects measurement error in the state unemployment rate. Our approach is to use only the part of the variation in $T_{s, t}^{*}$ induced by the UI error $\hat{T}_{s, t}$ to identify the effects of benefit extensions on state-level outcomes. The remainder of this subsection describes how we operationalize the measurement error component $\hat{T}_{s, t}$.

An important step in our methodology is to use the revised unemployment rate to proxy for the true unemployment rate $u_{s, t}$ used in equation (3) to construct $T_{s, t} .{ }^{5}$ We start by detailing the measurement of the real-time and revised unemployment rates that underlie $\hat{T}_{s, t}$. The Local Area Unemployment Statistics (LAUS) program at the BLS produces estimates of state-level unemployment rates. Unlike the national unemployment rate, which derives directly from counts from the Current Population Survey (CPS) of households, state unemployment rates incorporate auxiliary information to overcome the problem of small sample sizes at the state level

5. We later show that our main conclusions remain unchanged if the revised unemployment rate also contains measurement error and we provide additional results using an alternative proxy of the true unemployment rate. While the IUR also enters into the determination of $T_{s, t}^{*}$, the real-time IUR uses as inputs administrative data on UI payments and covered employment and contains minimal measurement error, with a standard deviation of the real-time error in the IUR of 0.02 percentage point. Because revisions in the IUR do not meaningfully affect $\hat{T}_{s, t}$ we do not discuss them further. 
(roughly 1,000 labor force participants for the median state). Better source data and improved statistical methodology imply substantial revisions in the estimated unemployment rate over time.

1. Real-time Unemployment Rate $u_{s, t}^{*}$. The real-time unemployment rate is calculated as the ratio of real-time unemployment to real-time unemployment plus employment. The BLS uses a state-space filter to estimate separately real-time counts of unemployed and employed persons (see Online Appendix A for additional details). For unemployment, the observed variables are the CPS count of unemployed individuals in the state and the number of insured unemployed. For employment, the observed variables are the CPS count of employed individuals and the level of payroll employment in the state from the Current Employment Statistics (CES) program. From 2005 to 2014, the procedure also included a real-time benchmarking constraint that allocated pro rata the residual between the sum of filter-based levels across states and the total at the census division or national level. Finally, in 2010 the BLS began applying a one-sided moving average filter to the state-space filtered and benchmarked data.

2. Revised Unemployment Rate $u_{s, t}$. The BLS publishes revisions of its estimates of the state unemployment rates. Revisions occur for three reasons. First, the auxiliary data used in the estimation-insured unemployment and payroll employment-are updated with comprehensive administrative data not available in real time. ${ }^{6}$ Second, the BLS incorporates the entire time series available at the time of the revision into its model, replacing the state-space filter with a state-space smoother and the one-sided moving-average filter with a symmetric filter. Third, the BLS periodically updates its estimation procedure to reflect methodological improvements. Most recently, in 2015 the BLS replaced the external real-time benchmarking constraint with a benchmarking constraint internal to the state-space model, improved the treatment of state-specific

6 . The revisions to the insured unemployment data reflect corrections of the administrative records, explaining why they are quite small. The annual revision of the CES state employment data replaces state-level real-time monthly employment based on a survey of approximately 400,000 establishments with administrative data derived from tax records covering a virtual universe of private sector employment. 
outliers in the CPS, and improved the seasonal adjustment procedure. The Bureau of Labor Statistics (2015) describes these changes as resulting in "more accurate and reliable estimates." We investigate the importance of different components of the revision process in Online Appendix Table A1 by regressing the unemployment rate measurement error $\hat{u}_{s, t}$ on the components. We find that the 2015 methodological update and the treatment of outliers account for the largest amount of the variation in $\hat{u}_{s, t}$. Importantly, the incorporation of the full time series at the time of revision accounts for very little of the variation in $\hat{u}_{s, t}$.

3. Implementation. To separate $T_{s, t}^{*}$ into the component $T_{s, t}$ based on the revised unemployment rate data and the UI error $\hat{T}_{s, t}$, we use the weekly trigger notices produced by the Department of Labor (DOL). Each week the DOL produces a trigger notice that contains for each state the most recent available moving averages of IUR and TUR, the ratios of IUR and TUR relative to previous years, and information on whether a state has any weeks of EB available and whether it has adopted optional triggers for EB status. During periods with emergency compensation programs, the DOL also produces separate trigger notices with the relevant input data and status determination for the emergency programs. We scraped data for EB notices from 2003 to 2015 and for the EUC 2008 programs from the DOL's online repository. The TEUC notices are not available online but were provided to us by the DOL. Finally, the DOL library in Washington, DC contains print copies of trigger notices before 2003, which we scanned and digitized. ${ }^{7}$ We augment these data with monthly real-time unemployment rates by digitizing archived releases of the monthly state and local unemployment reports from the BLS.

We use the revised unemployment data as of 2015 as inputs into the trigger formulas described in Appendix Table A.1 to calculate $T_{s, t}$. The UI error then equals $\hat{T}_{s, t}=T_{s, t}^{*}-T_{s, t}{ }^{8}$ To

7. The URL for the online data is http://www.oui.doleta.gov/unemploy/claims arch.asp. The library could not locate notices for part of 1998 . We also digitized notices for the EUC program in operation between 1991 and 1994. However, we found only a few nonzero UI errors. We therefore exclude this period from our analysis and start in 1996, which is the year in which the BLS began using statespace models to construct real-time unemployment for all 50 states.

8. States have the option of whether to adopt two of the triggers for EB status. We follow the actual state laws in determining whether to apply the optional triggers. A complication arises with a temporary change in the law between De- 
TABLE II

Accuracy of Our Algorithm for Calculating Ui Benefit Extensions

\begin{tabular}{lccccc}
\hline & TEUC02 & EUC08 & \multicolumn{2}{c}{ EB } & Total \\
\cline { 4 - 5 } & $2002-2003$ & $2008-2013$ & $1996-2007$ & $2008-2015$ & \\
\hline Original trigger notices & & & & & \\
$\quad$ Same as our algorithm & 3,982 & 14,291 & 25,541 & 19,915 & 63,729 \\
Different from our algorithm & 18 & 9 & 9 & 35 & 71 \\
Corrected trigger notices & & & & & \\
$\quad$ Same as our algorithm & 3,999 & 14,300 & 25,548 & 19,946 & 63,793 \\
Different from our algorithm & 1 & 0 & 2 & 4 & 7 \\
\hline \hline
\end{tabular}

Notes. The table reports the number of state-weeks where applying our algorithm to real-time unemployment rate data gives the same UI benefit tier eligibility as the published DOL trigger notices. The top panel compares our algorithm to the raw trigger notices. In the bottom panel, we have corrected the information in the raw trigger notices when we find conflicting accounts in either contemporary media sources or in the text of state legislation.

verify the accuracy of our algorithm for constructing $T_{s, t}$, we apply the same algorithm to the real-time unemployment rate data and compare the duration of extensions $T_{s, t}^{*}$ implied by our algorithm to the actual duration reported in the trigger notices. Our algorithm does extremely well, as shown in Table II. Of 63,800 possible state-weeks, our algorithm agrees exactly with the trigger notices in all but seven cases. ${ }^{9}$

cember 17, 2010, and December 31, 2013. The EB total unemployment rate trigger requires the (three-month) moving average of the unemployment rate in a state to exceed $110 \%$ of its level in the same period in either of the two previous years. With unemployment in many states still high at the end of 2010 but no longer rising, Congress temporarily allowed states to pass laws extending the lookback period by an additional year. Many states passed such laws in the week in which the two-year lookback period would have implied an expiration of EB. When we use the revised unemployment rate to construct the duration of benefits under the EB program, we find that five states would have lost eligibility for EB earlier than in reality. Therefore, in constructing $T_{s, t}$, we assume that states would have adopted the three-year lookback option earlier had the duration of benefits under the EB program followed the revised rather than the real-time unemployment rate. Specifically, we set to zero the UI error from the EB program in any week in which a state had not adopted the three-year lookback trigger, the state did eventually adopt the three-year lookback trigger, and the UI error would have been zero had the state adopted the three-year lookback trigger in that week. This change affects a negligible fraction of observations in our sample (a total of 20 state-week observations).

9. Our algorithm does better than the trigger notices, in the sense that it identifies more than 50 instances where the trigger notices report an incorrect duration or aspect of UI law that we subsequently correct using contemporary local media sources, by comparing to the real-time unemployment rate data reported in LAUS press releases or by referencing state legislation. We suspect but cannot confirm 


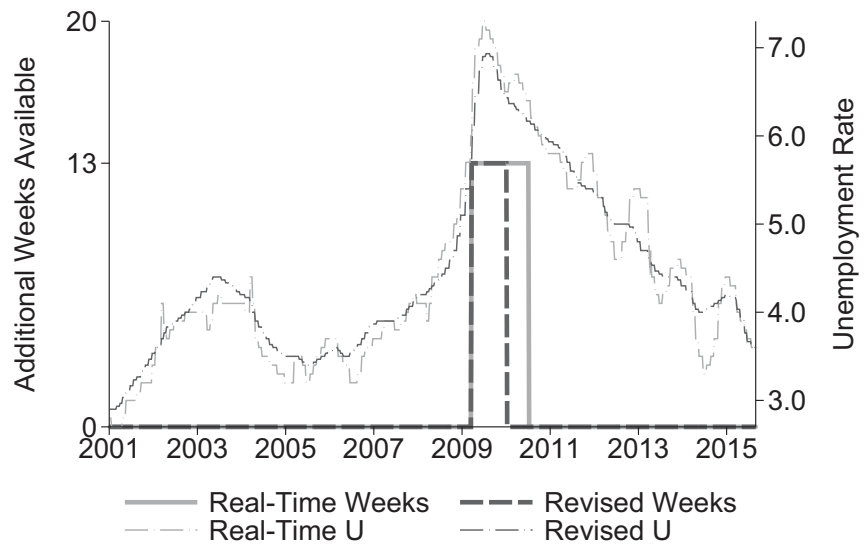

FIGURE I

Extended Benefits and Unemployment in Vermont

The figure plots the actual duration of benefits $T_{s, t}^{*}$ and the duration based on the revised data $T_{s, t}$ (left axis) together with the real-time $u_{s, t}^{*}$ and revised unemployment rates $u_{s, t}$ (right axis).

We use the EB program in the state of Vermont to illustrate the two components. Figure I plots four lines. The solid step function in light gray shows the additional weeks of benefits available to eligible unemployed in Vermont in each calendar week, $T_{\mathrm{VT}, t}^{*}$. This series depends on the most recently reported threemonth moving-average real-time unemployment rate, plotted by the dashed light gray line. The dashed step function in dark gray shows $T_{\mathrm{VT}, t}$, the additional weeks of benefits that would have been available in Vermont using the revised unemployment rate series plotted by the dashed dark gray line.

Vermont extended its benefits by 13 weeks in the beginning of 2009. Because the real-time and the revised unemployment rates move closely together in this period, Vermont would have triggered a benefits extension using either the real-time or the revised data as an input in the trigger formula. The unemployment rate peaks at the end of 2009. As the

that the remaining discrepancies also reflect mistakes in the trigger notices. A number of previous papers have relied on information contained in the trigger notices (Rothstein 2011; HMM and HKMM; Marinescu 2017). Our investigation reveals that while small in number, uncorrected mistakes in the trigger notices could induce some attenuation bias. 
unemployment rate starts to decline, a UI error occurs. In the beginning of 2010, the real-time unemployment rate temporarily increases by a small amount, whereas the revised rate continues to decline steadily. Under the revised data, EB should have been discontinued at the beginning of 2010. However, under the real-time data, EB remained in place until roughly the middle of 2010. The UI error $\hat{T}_{\mathrm{VT}, t}$, which is the difference between the dark and light gray step functions, takes the value of 13 weeks during the first part of 2010. In Online Appendix A we show that Vermont's UI error is entirely accounted for by the 2015 methodological improvement in the LAUS statistical model.

\section{III.B. UI Error Innovations}

The UI error $\hat{T}_{s, t}$ is a serially correlated process because the underlying measurement error in unemployment $\hat{u}_{s, t}$ is serially correlated, as shown in Figure I for Vermont. ${ }^{10}$ When a variable $\hat{T}_{s, t}$ is serially correlated over time and its leads and lags affect the dependent variable $y_{s, t}$, regressing $y_{s, t}$ on $\hat{T}_{s, t}$ generates an omitted variable bias. We follow the macroeconomic approach of plotting impulse responses with respect to structural innovations to overcome this difficulty. If UI errors arise independently of other economic variables, then the structural innovation is simply the unexpected component of the UI error. We therefore define:

$$
\epsilon_{s, t}=\hat{T}_{s, t}-\mathbb{E}_{t-1} \hat{T}_{s, t} .
$$

We implement three methods to identify the unexpected component in the UI error $\epsilon_{s, t}$. Our preferred approach allows the UI error $\hat{T}_{s, t}$ to follow a first-order discrete Markov chain with probability $\pi_{T}\left(\hat{T}_{s, t+1}=x_{j} \mid \hat{T}_{s, t}=x_{i} ; u_{s, t}, t\right)$ that $\hat{T}$ transitions from a value $x_{i}$ to a value $x_{j}$. A Markov chain is more general than an autoregressive process. Indeed, inspection of the time series of the UI errors in Figure I reveals a stochastic process better described by occasional discrete jumps than by a smoothly evolving diffusion. The transition probabilities may depend on the unemployment rate and calendar time because the mapping from a measurement error in the unemployment rate to a UI

10. The persistence in the UI error reflects both the UI law (once triggered onto a tier, a state must remain on for at least 13 weeks) and serial correlation in $\hat{u}_{s, t}$. To give a sense of the latter, the first eight autocorrelation coefficients of $\hat{u}_{s, t}$ are $0.78,0.63,0.52,0.45,0.40,0.35,0.32$, and 0.29 . 
error depends on whether the measurement error occurs in a region of the unemployment rate space sufficiently close to a trigger threshold. ${ }^{11}$ In practice, we aggregate $\hat{T}_{s, t}$ up to a monthly frequency, form a vector of discrete possible values of $x$ from one-half-standard-deviation-wide bins of $\hat{T}_{s, t}$, and estimate each probability $\pi_{T}\left(\hat{T}_{s, t+1}=x_{j} \mid \hat{T}_{s, t}=x_{i} ; u_{s, t}, t\right)$ as the fraction of transitions of the UI error from $x_{i}$ to $x_{j}$ for observations in the same unemployment rate and calendar time bin. Finally, once we have estimated the transition probabilities of the Markov process, we calculate the expectation $\mathbb{E}_{t-1} \hat{T}_{s, t}$ and form the UI error innovation $\epsilon_{s, t}$ using equation (5). ${ }^{12}$

In sensitivity exercises, we show that our results are robust to two alternative processes for $\hat{T}_{s, t}$ which impose additional structure. First, we obtain the innovations by first-differencing the UI error, $\epsilon_{s, t}=\hat{T}_{s, t}-\hat{T}_{s, t-1}$. This transformation is simpler than a first-order discrete Markov chain but comes at the cost of imposing a martingale structure on the UI error. Second, we obtain the innovations as the residual from a regression of $\hat{T}_{s, t}$ on lags of itself (and any covariates). This approach imposes smooth autoregressive dynamics on the process for $\hat{T}_{s, t}$ and is equivalent to estimating impulse responses with respect to $\hat{T}_{s, t}$ directly while controlling for lags of the UI error.

\section{III.C. Empirical Specification}

We now summarize our empirical methodology and state the assumptions under which the measurement error approach allows us to identify the causal effect of unemployment benefit extensions on labor market outcomes. Three equations underlie the approach.

11. For example, measurement error in the mid-2000s does not cause a UI error for Vermont in Figure I because the unemployment rate is far below the threshold for triggering an extension of benefits. Conditioning on calendar time reflects the time variation in UI laws and triggers due to enactment of an emergency compensation program.

12. A trade-off exists between finer partitioning of the state-space and retaining sufficient observations to make the exercise nontrivial. We estimate separate transition matrices for each of the following sequential groupings, motivated by the divisions shown in Appendix Table A.1: December 2008-May 2012 and $5.5 \leqslant u_{s, t}<7$; December 2008-May 2012 and $7 \leqslant u_{s, t}<8.5$; December 2008-May 2012 and $u_{s, t} \geqslant 8.5$; June 2012-December 2013 and $5.5 \leqslant u_{s, t}<7$; June 2012December 2013 and $7 \leqslant u_{s, t}<9$; June 2012-December 2013 and $u_{s, t} \geqslant 9$; January $2002-$ December 2003 and $u_{s, t} \geqslant 5.5 ; u_{s, t} \geqslant 5.5 ; u_{s, t}<5.5$. We have experimented with coarser groupings and larger bins of $\hat{T}_{s, t}$ with little effect on our results. 
Equation (1) relates a labor market outcome $y_{s, t}$ to contemporaneous values, lags, and leads of observed duration of benefits $T_{s, t}^{*}$. Equation (4) decomposes $T_{s, t}^{*}$ into the component that depends on fundamentals and the component that reflects measurement error, $T_{s, t}^{*}=T_{s, t}+\hat{T}_{s, t}$. Finally, equation (5) defines the UI error innovation $\epsilon_{s, t}=\hat{T}_{s, t}-\mathbb{E}_{t-1} \hat{T}_{s, t}$.

Our empirical specification is an OLS local projection of an outcome $y$ in state $s$ at horizon $h$ on the UI error innovation $\epsilon_{s, t}:{ }^{13}$

$$
y_{s, t+h}=\beta(h) \epsilon_{s, t}+v_{s, t+h} .
$$

To relate $\beta(h)$ to the structural coefficients $\{b(-j)\}_{j=-\infty}^{\infty}$ in equation (1), we substitute equations (4) and (5) into equation (1) for horizon $h$ :

$$
\begin{aligned}
& y_{s, t+h}=b(h)\left(\mathbb{E}_{t-1} \hat{T}_{s, t}+T_{s, t}+\epsilon_{s, t}\right) \\
& (7)+\sum_{j=-\infty, j \neq 0}^{h} b(h-j) T_{s, t+j}^{*}+\sum_{j=h+1}^{\infty} b(h-j) \mathbb{E}_{t+h} T_{s, t+j}^{*}+\eta_{s, t+h} .
\end{aligned}
$$

Using equation (7), the probability limit from estimating equation (6) with OLS is:

$$
\begin{aligned}
\operatorname{plim} \beta(h)= & b(h)+\frac{\operatorname{Cov}\left(b(h)\left(\mathbb{E}_{t-1} \hat{T}_{s, t}+T_{s, t}\right)+\eta_{s, t+h}, \epsilon_{s, t}\right)}{\operatorname{Var}\left(\epsilon_{s, t}\right)} \\
& +\sum_{j=-\infty, j \neq 0}^{h} \frac{\operatorname{Cov}\left(T_{s, t+j}^{*}, \epsilon_{s, t}\right)}{\operatorname{Var}\left(\epsilon_{s, t}\right)} b(h-j) \\
& +\sum_{j=h+1}^{\infty} \frac{\operatorname{Cov}\left(\mathbb{E}_{t+h} T_{s, t+j}^{*}, \epsilon_{s, t}\right)}{\operatorname{Var}\left(\epsilon_{s, t}\right)} b(h-j) .
\end{aligned}
$$

13. We ignore covariate terms for now to focus on the interpretation of the dynamic responses. Ramey (2016) extensively surveys the use of this approach to constructing impulse responses and Stock and Watson (forthcoming) provide a detailed econometric treatment. Our implementation follows Romer and Romer (1989) and Jordà (2005) in directly estimating the horizon $h$ response to a shock. 
We make the identifying assumptions:

$$
\operatorname{Cov}\left(\mathbb{E}_{t-1} \hat{T}_{s, t}, \epsilon_{s, t}\right)=\operatorname{Cov}\left(T_{s, t+j}^{*}, \epsilon_{s, t}\right)=0, \forall j<0,
$$

$$
\operatorname{Cov}\left(b(h) T_{s, t}+\eta_{s, t+h}, \epsilon_{s, t}\right)=0 .
$$

Equation (9) says that $\epsilon_{s, t}$ should be orthogonal to variables determined in period $t-1$ or earlier because $\epsilon_{s, t}$ is a time $t$ innovation. ${ }^{14}$ This assumption makes clear the purpose of constructing the innovations-the covariances of $\epsilon_{s, t}$ with lagged UI durations drop out of equation (8). Equation (10) states that the UI error innovation is orthogonal to the economic fundamentals that determine $\eta_{s, t+h}$ and $T_{s, t}$, which is valid if the unemployment rate measurement error that gives rise to the UI error is random with respect to the economic fundamentals. ${ }^{15}$ Imposing these assumptions on equation (8) yields:

$$
\operatorname{plim} \beta(h)=b(h)+\sum_{j=1}^{\infty} \frac{\operatorname{Cov}\left(\mathbb{E}_{t+h} T_{s, t+j}^{*}, \epsilon_{s, t}\right)}{\operatorname{Var}\left(\epsilon_{s, t}\right)} b(h-j),
$$

where $\mathbb{E}_{t+h} T_{s, t+j}^{*}=T_{s, t+j}^{*} \forall j \leqslant h$.

To interpret equation (11), consider first the effect of a UI error innovation at horizon $h=0$. The coefficient $\beta(0)$ reflects both the contemporaneous direct effect from an increased receipt of benefits following a UI error, $b(0)$, and the product of the change in agents' expectations about future benefit duration caused by a UI error innovation, $\frac{\operatorname{Cov}\left(\mathbb{E}_{t} T_{s, t+j}^{*}, \epsilon_{s, t}\right)}{\operatorname{Var}\left(\epsilon_{s, t}\right)}$, and the effect of future UI duration increases on current variables, $b(h-j)$. The change in expectations of future policy appropriately incorporates both the perceived persistence of a UI error and any effect of a UI error on actual unemployment, which feeds back into future UI duration. Thus, specification (6) estimates the policy-relevant effect of a change in UI benefits on labor market outcomes. More generally, the coefficients $\beta(h)=\mathbb{E}\left[y_{s, t+h} \mid \hat{T}_{s, t}=\right.$ $\left.1, \hat{T}_{s, t-1}, \hat{T}_{s, t-2}, \ldots\right]-\mathbb{E}\left[y_{s, t+h} \mid \hat{T}_{s, t}=0, \hat{T}_{s, t-1}, \hat{T}_{s, t-2}, \ldots\right]$ for $h=0$,

14. In our sample, the correlation coefficient of $\epsilon_{s, t}$ and $\mathbb{E}_{t-1} \hat{T}_{s, t}$ or lags of $T_{s}^{*}$, never exceeds 0.04 in absolute value.

15. This statement ignores a subtlety caused by the nonlinear mapping which transforms $\hat{u}_{s, t}$ into $\hat{T}_{s, t}$. See note 22 for further discussion and how controlling for lags of $u_{s, t}$ addresses it. 
$1,2, \ldots$ trace out the impulse response function of $y$ with respect to an unexpected one-month increase in the UI error. ${ }^{16}$

\section{Data And Summary Statistics}

We draw on a number of sources to obtain data for state-level outcome variables. From the BLS, along with the revised unemployment rate, we use monthly payroll employment from the CES program and monthly labor force participation from the LAUS program. The CES data have the advantage of deriving (after revisions) directly from administrative tax records. We obtain data on the number of UI payments across all programs by state and month from the DOL ETA 539 and ETA 5159 activity reports and from special tabulations for the July 2008 to December 2013 period. ${ }^{17}$ We obtain monthly data on vacancies from the Conference Board Help Wanted Print Advertising Index and the Conference Board Help Wanted Online Index. We use the first for 1996-2003 and aggregate local areas up to the state level. We use the online index for 2007-2015. The print index continues until June 2008 and the online index begins in 2005. However, the two indexes exhibit conflicting trends between 2004 and 2006 as vacancy posting gradually transitioned from print to online, and we exclude this period from our analysis of vacancies. ${ }^{18}$ Our

16. A closely related variant of equation (6) is to instead estimate equation (1) treating $T_{s, t}^{*}$ as an endogenous variable and using $\epsilon_{s, t}$ as an excluded instrument. Applying the analogous algebra in the text to the formula for a 2SLS coefficient, one can show that under our identifying assumptions the interpretation of the IV coefficient is the same as the interpretation of $\beta(h)$. However, the IV estimate relaxes the assumption that $\operatorname{Cov}\left(T_{s, t}, \epsilon_{s, t}\right)=0$ because any correlation between the two variables simply pushes the first-stage coefficient away from 1 . We report estimates from this IV specification in Table IX and cannot reject equality with the OLS estimates. Because OLS is more efficient and the randomness in unemployment rate errors provides a theoretical justification for the assumption, we make OLS our baseline specification.

17. These are found at http://www.ows.doleta.gov/unemploy/DataDownloads. asp and http://workforcesecurity.doleta.gov/unemploy/euc.asp respectively (accessed February 10, 2016). The data report the total number of UI payments each month. To express as a share of the total unemployed, we divide by the number of unemployed in the (revised) LAUS data and multiply by the ratio $\frac{7}{\text { days in month }}$ because the number of unemployed are a stock measure as of the CPS survey reference week.

18. The loss of these years has little effect on our results because these years contain very few UI errors. See Sahin et al. (2014) for a description of the vacancy data and a comparison to JOLTS. 
measure of worker wages, available at a quarterly frequency, is the earnings of all and of new workers from the Census Bureau Quarterly Workforce Indicators.

Table III reports summary statistics. Our sample covers the period between 1996 and 2015 for the 50 U.S. states. ${ }^{19}$ The error in the real-time state total unemployment rate, $\hat{u}_{s, t}$, has a mean of close to 0 but a standard deviation of 0.37 percentage point. Measurement error in the unemployment rate is spread across states and months as its standard deviation changes little after controlling for state and month fixed effects.

A potential concern is that there are too few or too small UI errors to identify significant effects of benefit extensions on macroeconomic outcomes. Table III shows that this is not true. There are 618 cases in which a state would have had a different duration of extensions using the revised data. Conditional on a UI error occurring, that is, $\hat{T}_{s, t} \neq 0$, the standard deviation of the UI error is larger than two months. ${ }^{20}$ The interquartile range is roughly 3.5 months. The fact that there is enough variation in the UI error relative to outcome variables, such as the unemployment rate, explains the small standard errors of our estimates below.

The average episode of a nonzero UI error lasts nearly 4 months and occurs when benefit extensions already provide an additional 11 months of UI eligibility. Most of these episodes occur during the Great Recession. As already discussed in Section III.B, measurement error in the unemployment rate $\hat{u}$ translates into a UI error $\hat{T}$ only if the state's unemployment rate is sufficiently near a trigger threshold. This fact explains why we construct $\hat{T}$ rather than using $\hat{u}$ directly and why the UI errors occur mostly in the Great Recession, a period when both the EUC program created additional trigger thresholds and most states had unemployment rates high enough for measurement error in the unemployment rate to translate into a UI error.

\section{Labor Market Effects of Benefit Extensions}

In this section we present impulse responses of labor market outcomes to UI benefit extensions. Motivated by our

19. We exclude months in which a benefit extension program had temporarily lapsed for at least half the month (June, July, and December 2010) and the months immediately following (August 2010 and January 2011).

20 . Throughout the article, when referring to months of benefit extensions we use the convention that one month equals 4.33 weeks. 


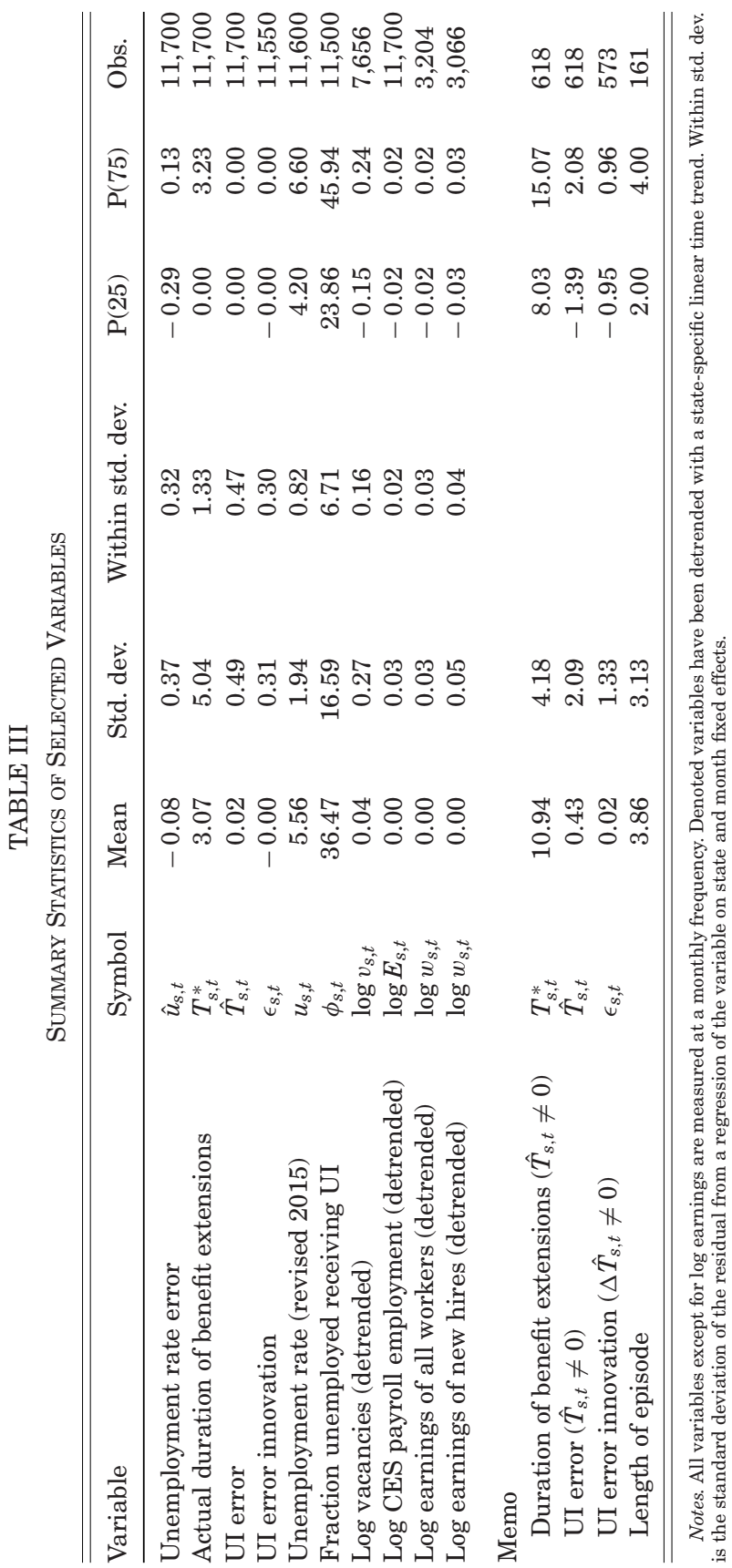


investigation of the sources of unemployment rate revisions, we begin our analysis under the assumption that the measurement error in the unemployment rate underlying $\epsilon_{s, t}$ is random. We discuss the interpretation of the impulse responses in Section V.B. Section V.C relaxes the assumption that $\epsilon_{s, t}$ is random. In Section V.D we discuss the possibility of measurement error in the revised unemployment rate and provide auxiliary evidence that the revised unemployment rate better measures true economic conditions than the real-time unemployment rate. Finally, Section V.E presents more sensitivity analyses.

\section{V.A. Baseline Results}

We measure the responses of labor market variables to a onemonth UI error innovation using equation (6) augmented with control variables for lags of the (true) unemployment rate and state and month fixed effects:

$$
y_{s, t+h}=\beta(h) \epsilon_{s, t}+\sum_{j=1}^{12} \gamma_{j}(h) u_{s, t-j}+d_{s}(h)+d_{t}(h)+v_{s, t+h},
$$

where $y_{s, t+h}$ is an outcome variable in state $s$ and period $t+h$, $\epsilon_{s, t}$ is the UI error innovation in state $s$ and period $t$, and $d_{s}(h)$ and $d_{t}(h)$ are state and month fixed effects. ${ }^{21}$ Including lags of the unemployment rate as controls approximates the experiment of comparing two states on similar unemployment paths until one receives an unexpected UI error. These covariates also directly address the fact that even when $\hat{u}_{s, t}$ is strictly exogenous, the nonlinear mapping from $\hat{u}_{s, t}$ to $\hat{T}_{s, t}$ depends on $u_{s, t-1} \cdot{ }^{22}$ We include

21. We can extend the calculations in Section III.C when covariates $\mathbf{X}_{s, t}$ are present in the regression by conditioning all covariances and variances on $\mathbf{X}_{s, t}$ and then adding the endogenous propagation of variables in $\mathbf{X}_{s, t}$, captured by the terms $\frac{\operatorname{Cov}\left(\mathbf{X}_{s, t+h}, \epsilon_{s, t} \mid \mathbf{X}_{s, t}\right)}{\operatorname{Var}\left(\epsilon_{s, t} \mid \mathbf{X}_{s, t}\right)}$, to equation (11). When we plot impulse responses of $u_{s, t+h}$ we continue to include both the fixed effect and the lagged values of $u_{s, t}$ in an OLS framework because the large time series (more than 200 monthly observations) exceeds the cross-sectional component (Alvarez and Arellano 2003).

22 . The mapping is easiest to see in a hypothetical example in which a single extension threshold $\bar{u}$ determines the extension of benefits. In this case, a positive UI error, $\hat{T}_{s, t}=T_{s, t}^{*}-T_{s, t}>0$, is associated with a low revised unemployment rate, $u_{s, t-1}^{*}>\bar{u}>u_{s, t-1}$, and the opposite for a negative UI error. Controlling for the lagged unemployment rate directly addresses any such correlation. We show in supplemental material that this correlation would have a minor affect on our estimates even without controlling for the lagged unemployment rate. The 12 lags 

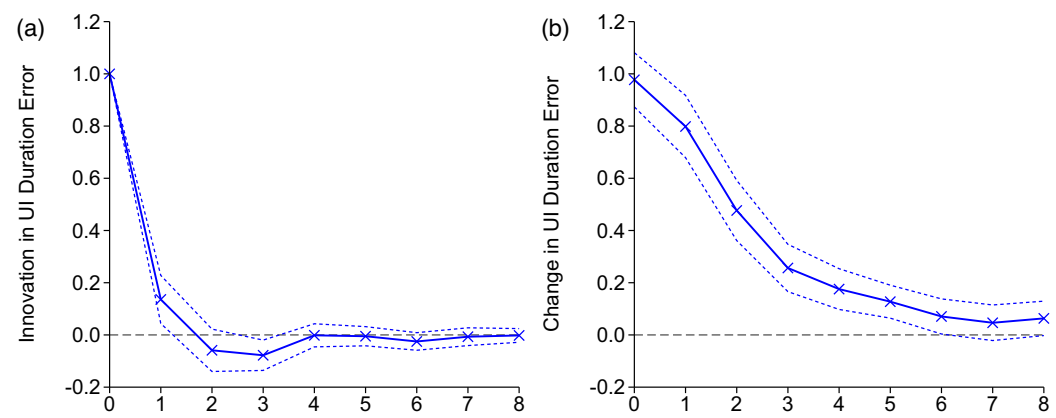

FIGURE II

\section{Serial Correlation}

The figure plots the coefficients on $\epsilon_{s, t}$ from the regression $y_{s, t+h}=\beta(h) \epsilon_{s, t}+$ $\sum_{j=1}^{12} \gamma_{j}(h) u_{s, t-j}+d_{s}(h)+d_{t}(h)+v_{s, t+h}$, where $y_{s, t+h}=\epsilon_{s, t+h}$ is the UI error innovation (left panel) or $y_{s, t+h}=\hat{T}_{s, t+h}$ is the UI error (right panel). The dashed lines denote the $90 \%$ confidence interval based on two-way clustered standard errors.

state and month fixed effects because they increase precision by absorbing substantial variation in our main outcome variables.

The coefficients $\beta(h)$ for $h=0,1,2, \ldots$ trace out the impulse response function of $y$ with respect to a one-month unexpected change in the UI error. The identifying assumption that $\epsilon_{s, t}$ is orthogonal to $v_{s, t+h}, \mathbb{E}\left[\epsilon_{s, t} \times v_{s, t+h} \mid\right.$ controls $]=0$, is valid if the underlying measurement error in the unemployment rate $\hat{u}_{s, t}$ that gives rise to $\epsilon_{s, t}$ is random.

Figure II shows impulse responses of the innovation $\epsilon$ and the UI error $\hat{T}$ to a one-month innovation $\epsilon$. In all figures, dashed lines report the $90 \%$ confidence interval based on standard errors two-way clustered by state and by month. The innovation exhibits essentially no serial correlation. The lack of serial correlation provides support for our choice of modeling $\hat{T}$ as a first-order Markov process. ${ }^{23}$ The UI error $\hat{T}$ rises one-for-one with $\epsilon$ on impact and then decays over the next few months with a half-life of roughly two months.

Figure III illustrates the main result of the article. The left panel shows the responses from regression (12) when the

of the unemployment rate also directly control for the small increment to the variation in the measurement error $\hat{u}$ accounted for by lags of the unemployment rate shown in Online Appendix Table A1.

23. Time aggregation from weekly to monthly frequency likely explains the small correlation between months $t$ and $t+1$, as an increase in $\hat{T}$ in week 3 or 4 of month $t$ would produce a positive innovation in both $t$ and $t+1$. 

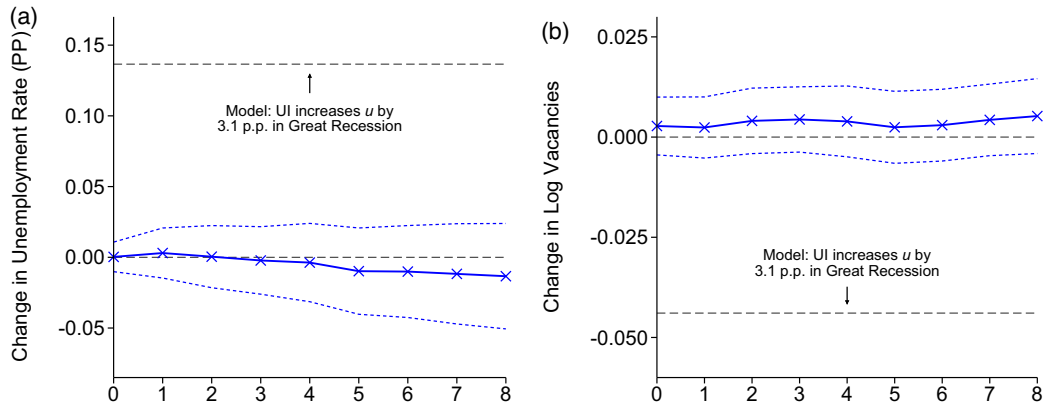

FIGURE III

Impulse Responses of Unemployment Rate and Log Vacancies

The figure plots the coefficients on $\epsilon_{s, t}$ from the regression $y_{s, t+h}=\beta(h) \epsilon_{s, t}+$ $\sum_{j=1}^{12} \gamma_{j}(h) u_{s, t-j}+d_{s}(h)+d_{t}(h)+v_{s, t+h}$, where $y_{s, t+h}=u_{s, t+h}$ is the unemployment rate (left panel) or $y_{s, t+h}=\log v_{s, t+h}$ is $\log$ vacancies (right panel). The dashed lines denote the $90 \%$ confidence interval based on two-way clustered standard errors.

left-hand-side variable is the (revised) unemployment rate. The unemployment rate barely responds to the increase in the duration of benefits. The point estimate for the response is essentially zero. The upper bound is roughly 0.02 percentage point. The data do not reject a zero response of the unemployment rate at any horizon. ${ }^{24}$

To give a sense of the small magnitude of the responses, in the same figure we plot a dashed line at roughly 0.14 percentage point. This is the response generated by a version of the standard DMP model discussed in Section VI and parameterized in a way that rationalizes a persistent increase of 3.1 percentage points in unemployment caused by the extension of benefits from 6 to 20 months in the Great Recession. Our baseline point estimate is more than six standard errors below this level.

The right panel of Figure III reports the response of vacancy creation. The macroeconomic effect of benefit extensions on unemployment may exceed the microeconomic effect because of a general equilibrium mechanism intermediated by vacancies. The mechanism posits that following the extension of benefits, firms

24. Clustering at the quarter and state level instead of the month and state level yields almost identical confidence bands to those shown in Figure III. For example, the standard error of the unemployment rate response at the one-month horizon would increase from 0.009 to 0.010 and the standard error at the fourmonth horizon is identical up to three decimal places. 

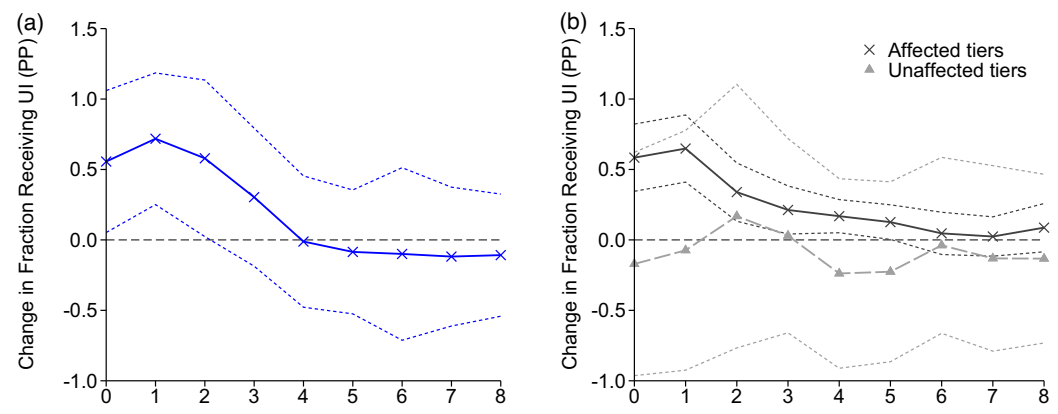

FiguRe IV

Impulse Response of Fraction Receiving UI

The figure plots the coefficients on $\epsilon_{s, t}$ from the regression $\phi_{s, t+h}=\beta(h) \epsilon_{s, t}+$ $\sum_{j=1}^{12} \gamma_{j}(h) u_{s, t-j}+d_{s}(h)+d_{t}(h)+v_{s, t+h}$. In the left panel, $\phi_{s, t+h}$ includes UI recipients in all tiers. The right panel plots separate impulse response functions for UI recipients in tiers with a UI error (solid dark gray line) and in tiers without a UI error (dashed light gray line). In the right panel, the sample starts in 2008. The dashed lines denote the $90 \%$ confidence interval based on two-way clustered standard errors.

bargain with unemployed who have a higher opportunity cost of working. The result is higher wages and lower firm profits from hiring, discouraging vacancy creation (HKMM). However, Figure III shows that vacancies are unresponsive to a UI error innovation. The dashed line plotted at -0.045 denotes the response of log vacancies in the version of the DMP model in Section VI parameterized such that the extension of benefits from 6 to 20 months caused unemployment in the Great Recession to remain persistently high.

Figure IV demonstrates that the absence of a response of unemployment and vacancies occurs despite a higher fraction of the unemployed receiving UI benefits following a UI error innovation. The left panel shows that upon impact, the fraction of unemployed receiving UI benefits increases by 0.5 percentage point. The fraction remains high for the next two months and then declines to zero. This response is reasonable. The innovations in the UI error take place when benefits have, on average, already been extended for roughly 11 months. Using CPS data we estimate that between $0.5 \%$ and $1 \%$ of unemployed workers would be affected by such an extension, implying a take-up rate in the range of estimates documented by Blank and Card (1991). The right panel of Figure IV splits the increase in UI receipt into recipients on tiers 
without a UI error (dashed light gray line with triangles) and recipients on tiers affected by the UI error (solid dark gray line with crosses). ${ }^{25}$ All of the additional take-up of UI benefits occurs among individuals on tiers directly affected by the UI error.

Finally, Table IV summarizes the responses of a number of labor market variables. The left panel reports the point estimates and standard errors at horizons 1 and 4 for the variables already plotted along with employment, labor force participation, and worker earnings. The right panel displays results for a slight modification of our baseline regression (12) in which we replace the dependent variable with its difference relative to the period before the UI error innovation occurs. If UI error innovations are uncorrelated with lagged outcome variables, then including the dependent variable in either levels or differences will yield a similar coefficient. ${ }^{26}$ Across all variables, we find economically negligible responses to a positive one-month innovation in the UI error. The standard errors rule out effects much larger in magnitude.

\section{V.B. Interpretation of Responses}

Our results provide direct evidence of the limited macroeconomic effects of increasing the duration of unemployment benefits around the neighborhood of a typical UI error, or by about three months after a state has already extended benefits by nearly

25 . We do not have UI receipt by tier for the EB or TEUC02 programs. Therefore, the sample in the right panel of Figure IV starts in 2008, and the sum of the two lines in the right panel does not equal the impulse response in the left panel, which is based on the full sample.

26. For $u_{s, t}$, the lags of the unemployment rate included in the baseline regression (12) make the differencing with respect to $u_{s, t-1}$ redundant, but for the other variables we have not imposed a zero effect in $t-1$ in the levels specification of the left panel of Table IV. We prefer the levels specification in the left panel because of a time-aggregation issue. An increase in $\hat{T}$ in week 4 of month $t-1$ that persists through month $t$ would be associated with an increase in $\epsilon_{s, t}$ and may also be correlated with variables in $t-1$. Indeed, we have already noted the small serial correlation of $\epsilon_{s, t}$ due to this time aggregation issue. The attenuation from differencing with respect to $t-1$ is likely quite small for variables based on the CPS (the unemployment rate and labor force participation rate) or the CES (payroll employment) which use as a reference period the week or pay period containing the 12th day of the month. Likewise, the reference period for the vacancy measure for month $t$ is from mid-month in $t-1$ to mid-month in month $t$. However, the problem is larger for the fraction of unemployed who receive UI, which counts all UI payments during the month, and for the wage measures, which include total earnings over the month. We account for this issue in Table III by taking a difference of these variables with respect to their $t-2$ value. 
one year. In this section we discuss the informativeness of this evidence for changes in labor market outcomes in response to other UI policies such as increasing benefits all the way from 26 to 99 weeks as observed in some states after the Great Recession.

We start by performing a linear extrapolation and then discuss the merits of this procedure. Extrapolating linearly the upper bound of a 0.02 percentage point increase in the unemployment rate with respect to a one-month UI error innovation, increasing benefits from 26 to 99 weeks would increase the unemployment rate by roughly $0.02 \times 17 \approx 0.3$ percentage point. Similarly, linearly extrapolating a lower bound of -0.03 percentage point yields a maximum decrease in the unemployment rate of 0.5 percentage point for an extension of benefits from 26 to 99 weeks. ${ }^{27}$

These calculations neglect two potentially important differences between the variation underlying our estimated impulse responses and a typical extension of benefits in the aftermath of the Great Recession. First, the response of labor market outcomes to an extension from a baseline level of 26 weeks may differ from the response to an extension from a baseline level of 70 weeks. Second, the UI errors have lower persistence relative to a policy that increases maximum benefits to 99 weeks as in the Great Recession. We discuss each difference in turn and argue that neither appears especially important in practice.

1. Baseline Level of Benefit Duration. The typical UI error in our sample causes an increase in the maximum potential duration of benefits starting from a baseline level of roughly 16.5 months. ${ }^{28}$ A concern for the linear extrapolation that we performed may be that labor market variables respond more

27. The lower bound encompasses the estimates of Di Maggio and Kermani (2015) who find a UI output multiplier of 1.9. To compare to Di Maggio and Kermani (2015), note that total EB and EUC payments between 2009 and 2013 were $\$ 50.5$ billion, $\$ 79.2$ billion, $\$ 58.7$ billion, $\$ 39.7$ billion, and $\$ 22.0$ billion. Applying a multiplier of 1.9 to the peak amount of $\$ 79.2$ billion in 2010 gives an increase in output in 2010 of $1.0 \%$ of GDP. An application of Okun's law yields a $0.3-0.5$ percentage point decline in the unemployment rate in that year.

28. The variation in the duration of benefits around a baseline level well beyond the six months of regular benefits is typical of studies based on cross-state variation. The reason is that cross-state variation in benefit duration concentrates in recessions when the first tier of emergency compensation uniformly increases benefit duration across all states and many states qualify for multiple additional tiers. For example, HKMM study county border pairs where the potential duration of benefits differs across the two counties. We calculate that the median maximum 
TABLE IV

RESPONSE OF VARIABLES TO UI ERROR INNOVATION

\begin{tabular}{lccccc}
\hline \hline & \multicolumn{2}{c}{ Levels } & & \multicolumn{2}{c}{ Differences } \\
\cline { 2 - 3 } \cline { 5 - 6 } Horizon & 1 & 4 & & 1 & 4 \\
\hline 1. Unemployment rate & 0.003 & -0.003 & & 0.003 & -0.003 \\
& $(0.009)$ & $(0.015)$ & & $(0.009)$ & $(0.015)$ \\
2. Log vacancies & 0.003 & 0.004 & & 0.001 & 0.002 \\
& $(0.004)$ & $(0.005)$ & & $(0.002)$ & $(0.003)$ \\
3. Fraction receiving UI & $0.751^{* *}$ & -0.039 & & $0.914^{* *}$ & 0.129 \\
& $(0.253)$ & $(0.263)$ & & $(0.291)$ & $(0.285)$ \\
4. Log CES payroll employment & 0.000 & 0.000 & & 0.000 & -0.000 \\
& $(0.000)$ & $(0.000)$ & & $(0.000)$ & $(0.000)$ \\
5. Labor force participation rate & 0.001 & 0.001 & & $0.012^{+}$ & 0.014 \\
& $(0.018)$ & $(0.022)$ & & $(0.007)$ & $(0.014)$ \\
6. Log earnings (all workers) & 0.001 & -0.001 & & 0.004 & 0.002 \\
& $(0.002)$ & $(0.002)$ & & $(0.004)$ & $(0.003)$ \\
7. Log earnings (new hires) & -0.000 & 0.004 & & -0.000 & 0.004 \\
& $(0.003)$ & $(0.004)$ & & $(0.004)$ & $(0.007)$ \\
\hline
\end{tabular}

Notes. Each cell reports the result from a separate regression of the dependent variable indicated in the left column on the innovation in the UI error $\epsilon_{s, t}$, controlling for state and period fixed effects and 12 monthly or 4 quarterly lags of $u_{s, t}$. For "Levels," the dependent variable enters in levels. For "Differences," the dependent variable enters with a difference relative to its value in $t-1$ (rows $1,2,4,5$ ) or $t-2$ (rows $3,6,7$ ). Standard errors clustered by state and time period are shown in parentheses. ${ }^{+},{ }^{* *}$ denote significance at the $10 \%$ and $1 \%$ levels, respectively.

to benefit extensions occurring around a lower baseline level of duration, as these extensions directly affect the eligibility of a larger fraction of unemployed.

Table V, Panel A assesses this possibility by allowing the effect of a UI innovation $\epsilon_{s, t}$ in regression (12) to vary depending on the baseline level of duration of benefits. Specifically, the table reports the effects on unemployment, vacancies, and claimants of a UI error innovation interacted with whether the extension of benefits occurs when the duration of extended benefits is above 10.5 months (so the duration of total benefits is above the median of 16.5 months). The first four columns show that the effect of a UI error innovation on the unemployment rate and vacancies does not vary significantly with the baseline duration of extensions. The fifth column shows a larger point estimate for the fraction of unemployed claiming UI in response to a UI error innovation when the baseline duration is lower, consistent with an extension

duration is roughly 16.5 months for the border county with the lower duration in the pair, the same as in our study. 
from a lower baseline level directly affecting a larger fraction of unemployed persons (however, this interaction is not statistically significant). The small response of unemployment and vacancies to a UI error even at low baseline levels of duration supports the plausibility of a linear extrapolation.

2. Persistence. The typical extension of benefits is more persistent than a typical UI error in our sample. ${ }^{29}$

Let us start with a discussion of why this difference might not matter. The fraction of the unemployed who become immediately eligible for benefits does not depend on the persistence of the extension. Therefore, as equation (11) shows, whether a benefit extension arises due to a UI error or not affects the immediate response of unemployment and vacancies only insofar as workers and firms have different expectations of future benefit eligibility depending on the source of the extension. Although we do not have direct evidence on this point, it seems unlikely that agents could distinguish in real time between an increase due to the UI error component $\hat{T}_{s, t}$ and an increase due to the component $T_{s, t}$, because doing so would require agents to know in real time the unemployment rate error made by the BLS. If agents do not distinguish the source of a change in benefit extension duration, then the impact response of labor market variables to a UI error equals the response to a typical extension of benefits even though realized subsequent extensions may differ. ${ }^{30}$

29. The duration of a typical benefit extension in our data has a half-life of 12.5 months as opposed to a half-life of roughly 2.5 months for a typical UI error. Although the extensions above 26 weeks around the Great Recession lasted for five years, no state experienced a benefit extension to the maximum of 99 weeks for the whole of the EUC program. Rather, adjustments to the EUC law frequently changed the maximum potential duration across states and changes in unemployment caused states to trigger off and on tiers. Moreover, the temporary nature of the authorization for the EUC program meant that during the Great Recession the average time remaining until the program's expiration was roughly five months.

30. Related to this point, the UI literature contains conflicting evidence on how forward-looking are potential unemployment benefit recipients with respect to future benefit eligibility. Card and Levine (2000) and Card, Chetty, and Weber (2007) estimate a small decline in exit hazard for regular benefit recipients when a benefit extension occurs. Johnston and Mas (forthcoming) find evidence of a decline in exit hazard for recipients far from the benefit extension but no effect on the behavior of recipients within 30 weeks of the extension. Ganong and Noel (2017) find a large decline in consumption when exhaustion occurs, suggesting 
TABLE V

Baseline Duration and Length of Episode

\begin{tabular}{|c|c|c|c|c|c|c|}
\hline \multirow{2}{*}{$\begin{array}{l}\text { Dependent variable } \\
\text { Horizon }\end{array}$} & \multicolumn{2}{|c|}{ Unemployment rate } & \multicolumn{2}{|c|}{ Log vacancies } & \multicolumn{2}{|c|}{ Fraction receiving } \\
\hline & 1 & 4 & 1 & 4 & 1 & 4 \\
\hline \multicolumn{7}{|l|}{ Panel A } \\
\hline$\epsilon_{s, t}$ & $\begin{array}{c}0.004 \\
(0.010)\end{array}$ & $\begin{array}{l}-0.003 \\
(0.018)\end{array}$ & $\begin{array}{c}0.002 \\
(0.008)\end{array}$ & $\begin{array}{c}0.007 \\
(0.010)\end{array}$ & $\begin{array}{c}0.925^{* *} \\
(0.249)\end{array}$ & $\begin{array}{l}-0.051 \\
(0.280)\end{array}$ \\
\hline$\epsilon_{s, t} \times\left[T_{s, t}>10.5\right]$ & $\begin{array}{l}-0.002 \\
(0.008)\end{array}$ & $\begin{array}{c}0.000 \\
(0.019)\end{array}$ & $\begin{array}{c}0.003 \\
(0.011)\end{array}$ & $\begin{array}{l}-0.006 \\
(0.012)\end{array}$ & $\begin{array}{l}-0.425 \\
(0.395)\end{array}$ & $\begin{array}{c}0.028 \\
(0.297)\end{array}$ \\
\hline \multicolumn{7}{|l|}{ Panel B } \\
\hline$\epsilon_{s, t}$ & $\begin{array}{c}0.008 \\
(0.011)\end{array}$ & $\begin{array}{c}0.008 \\
(0.019)\end{array}$ & $\begin{array}{c}0.002 \\
(0.005)\end{array}$ & $\begin{array}{c}0.004 \\
(0.006)\end{array}$ & $\begin{array}{c}0.596^{*} \\
(0.257)\end{array}$ & $\begin{array}{l}-0.345 \\
(0.226)\end{array}$ \\
\hline$\epsilon_{s, t} \times\left[\right.$ Length $\left._{s, t}>6\right]$ & $\begin{array}{l}-0.020 \\
(0.012)\end{array}$ & $\begin{array}{l}-0.042 \\
(0.027)\end{array}$ & $\begin{array}{c}0.003 \\
(0.012)\end{array}$ & $\begin{array}{l}-0.001 \\
(0.013)\end{array}$ & $\begin{array}{c}0.584 \\
(0.472)\end{array}$ & $\begin{array}{l}1.149^{*} \\
(0.569)\end{array}$ \\
\hline Observations & 10,850 & 10,700 & 7,084 & 6,932 & 10,750 & 10,600 \\
\hline
\end{tabular}

Notes. Each column of each panel reports the coefficients from a separate regression. All regressions control for state and month fixed effects and 12 lags of $u_{s, t}$. In Panel A, the UI error innovation $\epsilon_{s, t}$ is interacted with whether benefit duration without the error exceeds 10.5 months. In Panel B, the UI error innovation $\epsilon_{s, t}$ is interacted with whether the length of the episode during which the UI error remains nonzero exceeds six months. Standard errors two-way clustered by state and month are in parentheses. ** and ${ }^{*}$ denote significance at the $1 \%$ and $5 \%$ levels, respectively.

We next demonstrate that the magnitude of the responses of unemployment and vacancies does not depend significantly on the length of the UI error episode. Although this type of evidence does not allow us to directly infer agents' expectations about the persistence of the UI errors, the stability of responses across different realized lengths of UI error spells is consistent with the linear extrapolation. Table V, Panel B reports coefficients from interacting the UI innovation $\epsilon_{s, t}$ in our baseline regression (12) with an episode length of greater than six months, where an episode means the length of time a UI error remains nonzero. The median episode of longer than 6 months lasts a total of 11 months. The first two sets of columns show that unemployment and vacancies do not respond differentially during episodes of length greater than six months. The small response of unemployment and vacancies to UI errors of greater lengths again enhances the plausibility of a linear extrapolation. The third set of columns shows that the fraction of unemployed who are receiving benefits does increase in the length of the episode and especially at longer horizons.

agents do not anticipate the exhaustion. In Section VI we use the structure of the DMP model to show that the responses we estimated with respect to a one-month UI innovation imply limited macroeconomic effects of benefit extensions even if agents expect a benefit extension caused by a UI error to be more transitory than a benefit extension caused by an increase in unemployment. 
This difference is expected because, by construction, an episode of longer than six months has a direct effect on eligibility at the four-month horizon, whereas an episode shorter than six months might not.

\section{V.C. Robustness to Process for $\hat{u}_{s, t}$}

In Section III.A, we distinguished among three sources of revisions to the state unemployment rate. One of these, the use of a state-space smoother in the revision process, makes the revised unemployment rate in each month dependent on the full available time series of the input variables at the point of revision. This dependence raises a concern that the unemployment rate revision in month $t$ partly depends on realizations of variables after month $t$. Importantly for our empirical design, we found that this source of revisions contributes little to the variation in $\hat{u}_{s, t}$ and hence $\epsilon_{s, t}$. Nonetheless, we implement two alternative strategies that remain valid even if the BLS revisions process induces a correlation between $\hat{u}_{s, t}$ and the future path of variables.

1. Controlling for $\hat{u}_{s, t}$. We augment our baseline specification to:

$$
y_{s, t+h}=\beta(h) \epsilon_{s, t}+g\left(\left\{\hat{u}_{s, t}\right\}\right)+\sum_{j=1}^{12} \gamma_{j}(h) u_{s, t-j}+d_{s}(h)+d_{t}(h)+v_{s, t+h},
$$

where the flexible function $g($.$) may allow for leads, lags, and$ nonlinear transformations of the measurement error in the unemployment rate $\hat{u}_{s, t}$. Specification (13) controls directly for any correlation between functions of $\hat{u}_{s, t}$ and the future path of $y_{s, t+h}$, which may arise from the revision process.

To build intuition for specification (13), it helps to start with the case where $y_{s, t+h}=u_{s, t+h}$ and $g()=.\rho(h) \hat{u}_{s, t-1}$. Recalling that $\epsilon_{s, t}$ depends on data in period $t-1$ due to reporting lags, $\hat{u}_{s, t-1}$ controls for the measurement error in the unemployment rate during the same month as the data that determine $\epsilon_{s, t}$. The term $\rho(h) \hat{u}_{s, t-1}$, therefore, partials out any "normal" covariation between $\hat{u}_{s, t-1}$ and $u_{s, t+h}$ that might result from the revision process. The identification exploits the fact that the mapping between $\hat{u}_{s, t-1}$ and $\hat{T}_{s, t}$ is not strictly monotonic; there are many instances of measurement error in the unemployment rate that do not give rise 

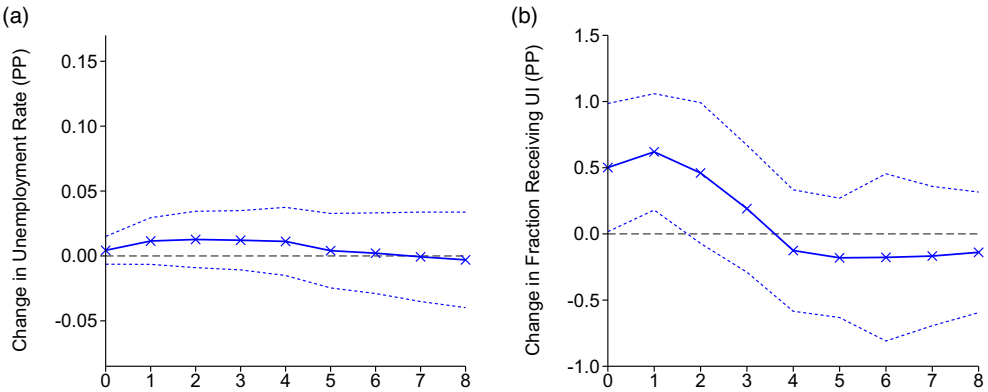

FiguRE V

Impulse Responses Controlling for Measurement Error $\hat{u}_{s, t}$

The figure plots the coefficients on $\epsilon_{s, t}$ from the regression $y_{s, t+h}=\beta(h) \epsilon_{s, t}+$ $\rho(h) \hat{u}_{s, t-1}+\sum_{j=1}^{12} \gamma_{j}(h) u_{s, t-j}+d_{s}(h)+d_{t}(h)+v_{s, t+h}$, where $y_{s, t_{h}}=u_{s, t+h}$ is the unemployment rate (left panel) or $y_{s, t_{h}}=\phi_{s, t+h}$ is the fraction of unemployed receiving UI on all tiers (right panel). The dashed lines denote the $90 \%$ confidence interval based on two-way clustered standard errors.

to a UI error, as illustrated in Figure I for Vermont. Formally, the identification assumption becomes $\mathbb{E}\left[\epsilon_{s, t} \times v_{s, t+h} \mid \mathbf{X}_{s, t}, \hat{u}_{s, t-1}\right]=0$. A sufficient condition for this to hold is that any correlation between the unemployment rate measurement error $\hat{u}_{s, t-1}$ and the future path of unemployment does not change if $\hat{u}_{s, t-1}$ causes a UI error, except through the direct response of future variables to the UI error. That is, $\mathbb{E}\left[u_{s, t+h} \mid \mathbf{X}_{s, t}, \hat{u}_{s, t-1}, \epsilon_{s, t}=\epsilon\right]=\mathbb{E}\left[u_{s, t+h} \mid \mathbf{X}_{s, t}, \hat{u}_{s, t-1}, \epsilon_{s, t}=\right.$ $0]+\beta(h) \epsilon=\Gamma(h) \mathbf{X}_{s, t}+\rho(h) \hat{u}_{s, t-1}+\beta(h) \epsilon$. Including leads, lags, or nonlinear transformations of $\hat{u}_{s, t-1}$ in the function $g($.) allows for the baseline correlation of $\hat{u}_{s, t-1}$ and $u_{s, t+h}$ to vary with the level or path of $\hat{u}_{s, t}$.

We begin in Figure $\mathrm{V}$ by reporting the impulse response functions for the unemployment rate $u_{s, t}$ and the total fraction receiving benefits $\phi_{s, t}$ based on specification (13) with only $\hat{u}_{s, t-1}$ added to the regression. Both impulse response functions appear nearly identical to those without the measurement error in the unemployment rate control. Specifically, the response of unemployment to a positive one-month UI error innovation is essentially zero while the fraction of unemployed receiving UI increases by roughly 0.5 percentage point.

We next allow for more flexible functions of the measurement error in the unemployment rate to enter into the specification. Table VI reports the one- and four-month responses of the unemployment rate, log vacancies, and the fraction of unemployed 


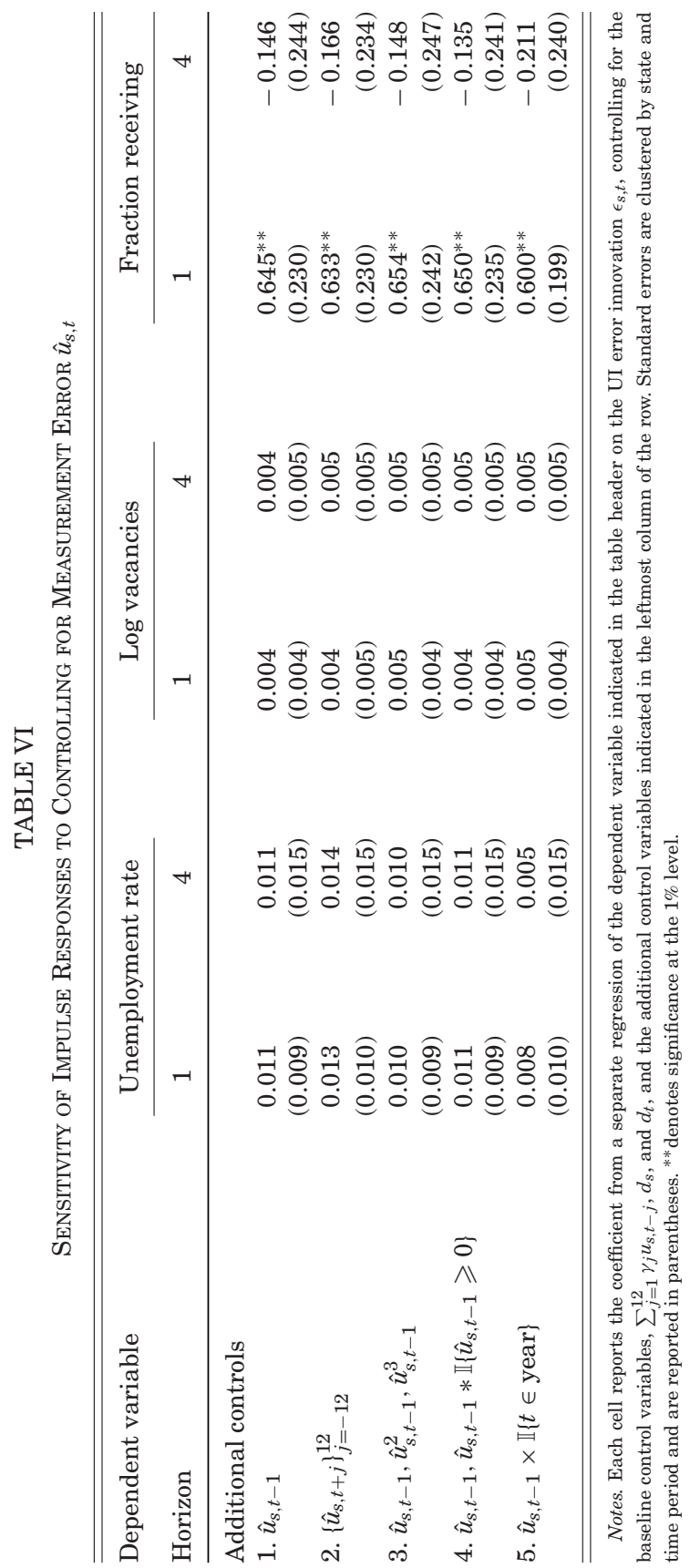


receiving UI. Each cell of the table reports the coefficient or standard error on the UI error innovation $\epsilon_{s, t}$ from a separate regression of the dependent variable in the column header on the UI error innovation, the baseline controls of 12 lags of the unemployment rate and state and month fixed effects, and the additional controls for the measurement error in the unemployment rate shown in the rows. The first row reports coefficients when controlling only for $\hat{u}_{s, t-1}$. The second row adds 12 leads and lags of $\hat{u}_{s, t}$. The third row incorporates a cubic in $\hat{u}_{s, t-1}$ as a control. The fourth row allows the coefficient on $\hat{u}_{s, t-1}$ to depend on the sign of the unemployment rate measurement error. The fifth row allows the coefficient on $\hat{u}_{s, t-1}$ to vary by year so that $\rho(h)$ could change with the introduction of real-time benchmarking in 2005 or the higher average unemployment during the Great Recession.

Our results do not change significantly in any of these specifications. In particular, the responses of unemployment and vacancies to a UI error innovation are always close to zero and never statistically significantly different from zero, whereas we always detect an increase in the fraction of the unemployed receiving benefits. The stability of the point estimates across specifications and the close similarity to the baseline results shown above reinforces the baseline identifying assumption in Section V.A.

2. Alternative Series for $\hat{T}_{s, t}$. Our second approach is to construct an alternative series for $\hat{T}_{s, t}$ that does not depend at all on the BLS unemployment rate revision process. Instead, we exploit CPS sampling error and generate an alternative unemployment rate series to proxy for the true unemployment rate $u_{s, t}$. Specifically, sampling error in the CPS contributes to a wedge between the insured unemployment rate in administrative records and the insured unemployment rate calculated from the CPS based on the number of CPS respondents reporting unemployment duration of less than 26 weeks and job loss as the reason for unemployment. Thus, we can infer CPS sampling error from the gap between these two measures and remove this sampling error to obtain an alternative proxy for $u_{s, t}$. In practice, we regress the BLS real-time unemployment rate $u_{s, t}^{*}$ on the contemporaneous values and 12 lags of the administrative insured unemployment rate and the labor force share of unemployed ineligible for regular UI taken directly from the CPS (i.e., duration greater than 26 weeks or not job loser), as well as state and month fixed effects. The $R^{2}$ of this regression is 0.96 . We use the fitted value of 

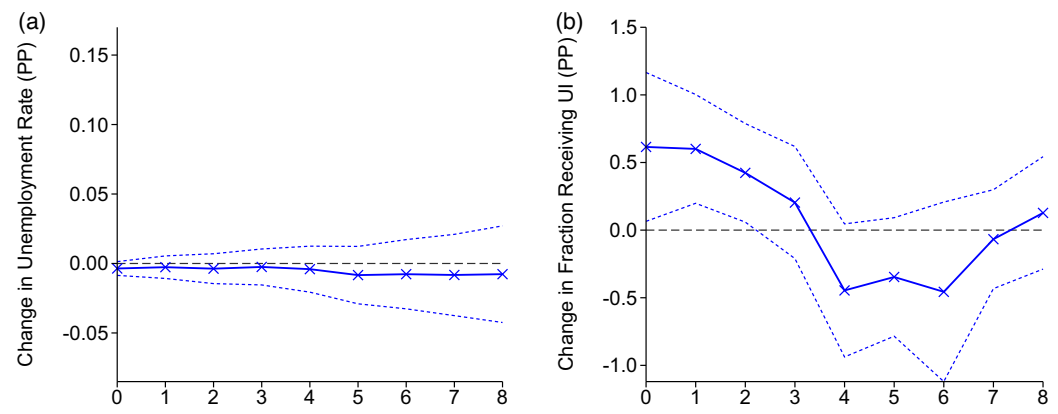

FIGURE VI

Impulse Responses Restricting Variation in Measurement Error

The figure plots the coefficients on $\epsilon_{s, t}$ from the regression $y_{s, t+h}=\beta(h) \epsilon_{s, t}+$ $\sum_{j=1}^{12} \gamma_{j}(h) u_{s, t-j}+d_{s}(h)+d_{t}(h)+v_{s, t+h}$, where $y_{s, t_{h}}=u_{s, t+h}$ is the unemployment rate (left panel) or $y_{s, t_{h}}=\phi_{s, t+h}$ is the fraction of unemployed receiving UI on all tiers (right panel). The dashed lines denote the $90 \%$ confidence interval based on two-way clustered standard errors.

this regression instead of the revised unemployment rate to proxy for $u_{s, t}$. We then construct the UI error $\hat{T}_{s, t}=T_{s, t}^{*}-T_{s, t}$, where in $T_{s, t}$ we use the new $u_{s, t}$ as the input into the mapping $f_{s, t}($.$) , and$ extract the innovations $\epsilon_{s, t}$ from the newly constructed UI error.

We estimate impulse responses using the specification (12) but with our alternative series for the UI error innovation $\epsilon_{s, t}$. Relative to the baseline results, the implementation here more tightly restricts the variation in UI duration to come from a particular source of error in the real-time unemployment rate. By construction, the UI error and the underlying measurement error in the unemployment rate now do not depend on the subsequent path of variables. Figure VI reports the impulse response functions for the unemployment rate and the total fraction receiving benefits based on the alternative series for the UI errors. Once again, both impulse response functions are quite similar to those reported above. The response of unemployment to a positive one-month UI error innovation is statistically indistinguishable from 0 while the fraction of unemployed receiving UI increases by roughly 0.8 percentage point.

\section{V.D. Information Content of Revisions}

Our baseline analysis assumes that the revised unemployment rate coincides exactly with the true unemployment rate. 
Yet if revisions to the unemployment rate contained little new economic information, then the error component of the benefit duration would be relatively uninformative for estimating the effects of benefit extensions on labor market outcomes. In addition, even if the revised data better reflect the economy's fundamentals, whether firms and workers respond to these fundamentals or to the data published in real time matters for the interpretation of our results.

In Online Appendix B we consider formally the case where the revised unemployment rate also contains measurement error with respect to the true unemployment rate. We obtain three results. First, the response of a variable to an innovation in $\hat{T}_{s, t}$ is attenuated toward zero if $T_{s, t}$, which is based on the revised unemployment rate, differs from the duration one would calculate based on the true unemployment rate. Intuitively, the true UI error is (roughly) a function of the difference between the real-time rate and the true unemployment rate, so if the revised rate equals the true unemployment rate plus random noise, then the UI error will inherit that noise. Second, the size of the attenuation bias is decreasing in the share of the variance of the innovation $\epsilon_{s, t}$ generated by true UI errors rather than measurement error in the revised unemployment rate. Third, if the revised unemployment rate is at least as good a measure of the true unemployment rate as the real-time rate, then the attenuation bias is bounded above by a factor of two.

The remainder of this section substantiates the informativeness of the revisions and argues that the revised unemployment rate better measures the true economic fundamental than the real-time rate. We have already presented two types of evidence consistent with the data revisions containing new information. First, Section III.A described the new source data and methodological improvements incorporated in the revisions process. Second, we would not have obtained the economically significant response of the fraction of unemployed receiving benefits if the revised data added only noise to the real-time estimates.

We now show that the revised unemployment rate better correlates with actual consumer spending. We estimate a horse-race specification:

$$
y_{s, t}=\beta^{\text {revised }} u_{s, t-2}^{\text {revised }}+\beta^{\text {real-time }} u_{s, t-2}^{\text {real-time }}+v_{s, t},
$$


where $y_{s, t}$ denotes either new auto registrations (from R.L. Polk) or new building permits (from the Census Bureau). Both series reflect spending done by a state's residents, derive from actual registration data, and have no mechanical correlation with either the real-time or the revised unemployment rate. We interpret the coefficients $\beta^{\text {revised }}$ and $\beta^{\text {real-time }}$ as the weights one should assign to the revised and real-time unemployment rates as statistical predictors of spending behavior. The unemployment rates enter the regression with a two-month lag to reflect the timing of the release of the LAUS state unemployment data, which usually occurs for month $t-1$ around the 20th day of month $t$. Therefore, agents at the beginning of month $t$ have access to the real-time unemployment rate for month $t-2$ but not for month $t-1$ or $t$. Agents do not know the revised unemployment rate for $t-2$ at the start of month $t$ but may respond to the economy's true fundamentals. Under the maintained assumption that higher unemployment is associated with lower spending, a finding of $\beta^{\text {revised }}$ $<0$ and $\beta^{\text {real-time }}=0$ provides support for the joint hypothesis that revised data improve the quality of measurement of economic fundamentals and that agents in real time base their decisions on these fundamentals and ignore the measurement error.

Table VII reports the results. Columns (1), (2), (4), and (5) show that both the revised and the real-time unemployment rates are negatively correlated with spending. The key results are shown in columns (3) and (6), in which we introduce jointly both variables in regression (14). For auto sales and building permits, we estimate $\beta^{\text {revised }}<0$ and $\beta^{\text {real-time }} \approx 0$. The estimates of $\beta^{\text {revised }}$ are close in magnitude to the estimates in columns (1) and (4); which exclude the real-time rate. Thus, the revised unemployment rate contains all the information about spending patterns; given knowledge of both series, one should put essentially no weight on the real-time data to predict actual spending.

Survey responses from the Michigan Survey of Consumers (MSC) provide further evidence that the revised unemployment data contains significant new information. The MSC asks 500 respondents each month a series of questions covering their financial situation and their views on the economy. For survey months in or after 2000, the Michigan Survey Research Center allowed us to merge external state-level data to anonymized responses. Because sample sizes are too small to aggregate to the state-month level, we instead run our horse-race regression at the individual 
TABLE VII

Spending Decisions and Unemployment Data

\begin{tabular}{|c|c|c|c|c|c|c|}
\hline & \multicolumn{6}{|c|}{ Dependent variable } \\
\hline & \multicolumn{3}{|c|}{ Auto sales } & \multicolumn{3}{|c|}{ Building permits } \\
\hline & (1) & (2) & (3) & (4) & (5) & (6) \\
\hline Revised $\mathrm{UR}_{s, t-2}$ & $\begin{array}{c}-0.42^{* *} \\
(0.11)\end{array}$ & & $\begin{array}{c}-0.52^{* *} \\
(0.13)\end{array}$ & $\begin{array}{c}-0.09^{* *} \\
(0.02)\end{array}$ & & $\begin{array}{c}-0.10^{* *} \\
(0.02)\end{array}$ \\
\hline Real-time $\mathrm{UR}_{s, t-2}$ & & $\begin{array}{c}-0.34^{* *} \\
(0.10)\end{array}$ & $\begin{array}{l}0.09^{+} \\
(0.05)\end{array}$ & & $\begin{array}{c}-0.07^{* *} \\
(0.02)\end{array}$ & $\begin{array}{c}0.01 \\
(0.02)\end{array}$ \\
\hline State FE & Yes & Yes & Yes & Yes & Yes & Yes \\
\hline Time FE & Yes & Yes & Yes & Yes & Yes & Yes \\
\hline Dep. var. mean & 5.4 & 5.4 & 5.4 & 0.5 & 0.5 & 0.5 \\
\hline Dep. var. std. dev. & 2.0 & 2.0 & 2.0 & 0.4 & 0.4 & 0.4 \\
\hline$R^{2}$ & 0.61 & 0.61 & 0.61 & 0.73 & 0.76 & 0.77 \\
\hline Observations & 10,096 & 9,847 & 9,847 & 15,800 & 12,147 & 12,147 \\
\hline
\end{tabular}

Notes. The dependent variable is indicated in the table header. The auto sales data come from R.L. Polk and correspond to the state of residency of the purchaser. The permits data are for new private housing units and come from the Census Bureau. Standard errors are clustered by state and month and denoted in parentheses. $* *, *,+$ denote significance at the $1 \%, 5 \%$, and $10 \%$ levels, respectively.

level and cluster standard errors by state and by month:

$$
y_{i, s, t}=\beta^{\text {revised }} u_{s, t}^{\text {revised }}+\beta^{\text {real-time }} u_{s, t}^{\text {real-time }}+\Gamma \mathbf{X}_{i, s, t}+v_{i, s, t} .
$$

Table VIII reports results for a subset of questions in the survey that we expect to correlate with the local unemployment rate. For brevity, we report only specifications with both unemployment rates. Averaging across the eight outcomes we consider, the first column shows that a higher revised unemployment rate is associated with worse subjective perceptions of economic conditions. It also shows that conditional on the revised unemployment rate, the real-time unemployment rate appears to add no information. This result repeats in various individual outcomes as shown in columns (2) to (9).

To summarize, the results in Tables VII and VIII provide direct additional evidence that the revised data better align with true economic fundamentals than the real-time data. Therefore, the conservative upper bound for the possible attenuation bias derived in Online Appendix B holds. Applying this upper bound to the confidence interval upper bound of a 0.02 percentage point increase in the unemployment rate in response to a one-month UI error yields a maximum response of 0.04 percentage point. 


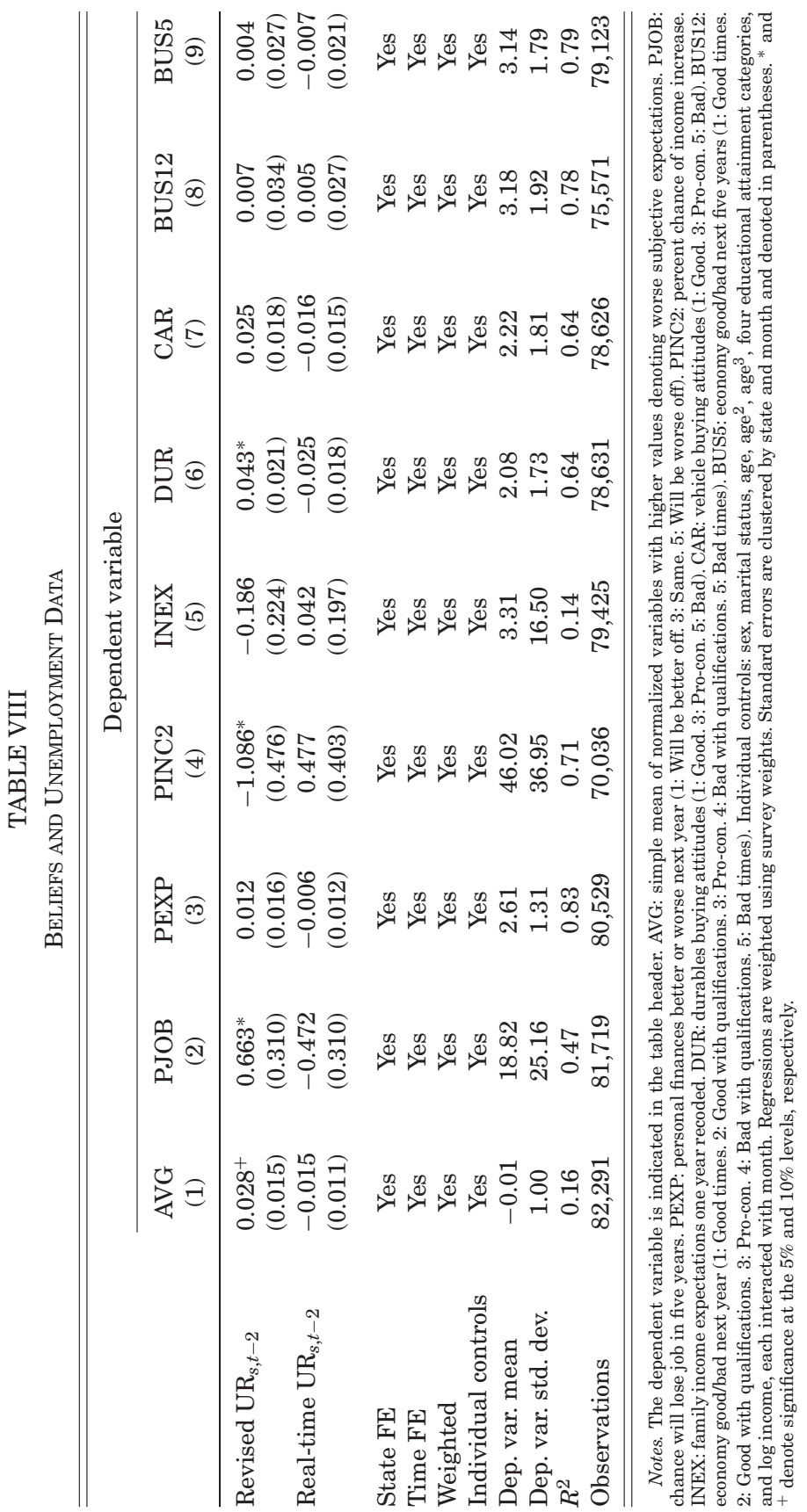


TABLE IX

Sensitivity of Impulse Responses to Alternative SPECifications

\begin{tabular}{|c|c|c|c|c|c|c|c|}
\hline \multicolumn{2}{|c|}{ Dependent variable } & \multicolumn{2}{|c|}{$\begin{array}{l}\text { Unemployment } \\
\text { rate }\end{array}$} & \multicolumn{2}{|c|}{$\begin{array}{c}\log \\
\text { vacancies }\end{array}$} & \multicolumn{2}{|c|}{$\begin{array}{l}\text { Fraction } \\
\text { receiving }\end{array}$} \\
\hline Horizon & & 1 & 4 & 1 & 4 & 1 & 4 \\
\hline Regressor & Controls & & & & & & \\
\hline 1. $\epsilon_{s, t}$ & $\left\{u_{s, t-j}\right\}_{j=1}^{12}, d_{s}, d_{t}$ & $\begin{array}{c}0.003 \\
(0.009)\end{array}$ & $\begin{array}{l}-0.003 \\
(0.015)\end{array}$ & $\begin{array}{c}0.003 \\
(0.004)\end{array}$ & $\begin{array}{c}0.004 \\
(0.005)\end{array}$ & $\begin{array}{l}0.751^{* *} \\
(0.253)\end{array}$ & $\begin{array}{l}-0.039 \\
(0.263)\end{array}$ \\
\hline 2. $\epsilon_{s, t}$ & $\left\{u_{s, t-j}\right\}_{j=1}^{12}, d_{s}, d_{t}, u_{s, t-1}^{\mathbb{I}}$ & $\begin{array}{c}0.003 \\
(0.009)\end{array}$ & $\begin{array}{l}-0.003 \\
(0.015)\end{array}$ & $\begin{array}{c}0.003 \\
(0.004)\end{array}$ & $\begin{array}{c}0.004 \\
(0.005)\end{array}$ & $\begin{array}{l}0.758^{* *} \\
(0.244)\end{array}$ & $\begin{array}{l}-0.033 \\
(0.245)\end{array}$ \\
\hline 3. $\epsilon_{s, t}$ & $d_{s}, d_{t}$ & $\begin{array}{l}-0.014 \\
(0.025)\end{array}$ & $\begin{array}{l}-0.023 \\
(0.026)\end{array}$ & $\begin{array}{c}0.006 \\
(0.005)\end{array}$ & $\begin{array}{c}0.007 \\
(0.006)\end{array}$ & $\begin{array}{l}0.684^{* *} \\
(0.235)\end{array}$ & $\begin{array}{l}-0.137 \\
(0.235)\end{array}$ \\
\hline 4. $\epsilon_{s, t}$ & None & $\begin{array}{l}-0.003 \\
(0.078)\end{array}$ & $\begin{array}{l}-0.029 \\
(0.078)\end{array}$ & $\begin{array}{c}0.015 \\
(0.010)\end{array}$ & $\begin{array}{l}0.019^{+} \\
(0.011)\end{array}$ & $\begin{array}{c}0.548 \\
(0.671)\end{array}$ & $\begin{array}{l}-0.478 \\
(0.709)\end{array}$ \\
\hline 5. $\Delta \hat{T}_{s, t}$ & $\left\{u_{s, t-j}\right\}_{j=1}^{12}, d_{s}, d_{t}$ & $\begin{array}{c}0.004 \\
(0.008)\end{array}$ & $\begin{array}{c}0.004 \\
(0.012)\end{array}$ & $\begin{array}{l}-0.000 \\
(0.003)\end{array}$ & $\begin{array}{l}-0.001 \\
(0.003)\end{array}$ & $\begin{array}{l}0.556^{* *} \\
(0.133)\end{array}$ & $\begin{array}{c}0.081 \\
(0.187)\end{array}$ \\
\hline 6. $\hat{T}_{s, t}$ & $\left\{\hat{T}_{s, t-j}, u_{s, t-j}\right\}_{j=1}^{12}, d_{s}, d_{t}$ & $\begin{array}{c}0.002 \\
(0.008)\end{array}$ & $\begin{array}{l}-0.003 \\
(0.014)\end{array}$ & $\begin{array}{l}-0.001 \\
(0.005)\end{array}$ & $\begin{array}{l}-0.001 \\
(0.005)\end{array}$ & $\begin{array}{l}0.911^{* *} \\
(0.266)\end{array}$ & $\begin{array}{c}0.012 \\
(0.242)\end{array}$ \\
\hline 7. $\Delta T_{s, t}^{*}$ & $\Delta \hat{T}_{s, t},\left\{u_{s, t-j}\right\}_{j=1}^{12}, d_{s}, d_{t}$ & $\begin{array}{c}0.006 \\
(0.007)\end{array}$ & $\begin{array}{c}0.011 \\
(0.012)\end{array}$ & $\begin{array}{l}-0.003 \\
(0.003)\end{array}$ & $\begin{array}{l}-0.003 \\
(0.004)\end{array}$ & $\begin{array}{l}1.018^{* *} \\
(0.178)\end{array}$ & $\begin{array}{l}0.369^{+} \\
(0.193)\end{array}$ \\
\hline 8. $T_{s, t}^{*}=\epsilon_{s, t}$ & $\left\{u_{s, t-j}\right\}_{j=1}^{12}, d_{s}, d_{t}$ & $\begin{array}{c}0.004 \\
(0.012)\end{array}$ & $\begin{array}{l}-0.004 \\
(0.019)\end{array}$ & $\begin{array}{c}0.004 \\
(0.005)\end{array}$ & $\begin{array}{c}0.005 \\
(0.007)\end{array}$ & $\begin{array}{l}1.029 * * \\
(0.291)\end{array}$ & $\begin{array}{l}-0.054 \\
(0.312)\end{array}$ \\
\hline
\end{tabular}

Notes. Each cell reports the coefficient from a separate regression of the dependent variable indicated in the column header on the right-hand-side variable indicated in the leftmost column of the row, controlling for the variables indicated in the second column of the row. In the last row, the specification is two-stage least squares with $T_{s, t}^{*}$ the endogenous variable and $\epsilon_{s, t}$ the excluded instrument. Standard errors clustered by state and time period are reported in parentheses. ${ }^{* *}$ and ${ }^{+}$denote significance at the $1 \%$ and $10 \%$ levels, respectively.

\section{V.E. Further Robustness}

Here we investigate the robustness of our main findings along various other dimensions. Table IX compares the one- and fourmonth responses of the unemployment rate, log vacancies, and the fraction of unemployed receiving UI in the baseline specification to the responses in alternative specifications. The first row of the table repeats the baseline results from Section V.A.

The second and third rows assess the practical importance of controlling for lags of the unemployment rate. In the second row, we additionally control nonparametrically for the lagged unemployment rate by partitioning the lagged unemployment rate into 0.5 percentage point-wide bins and adding indicator variables for whether the lagged rate lies in each bin. The third row removes the lags of the unemployment rate from the baseline specification. In all cases, we obtain very similar results to the baseline. The fourth row removes the lags of the unemployment rate and the state $d_{s}$ 
and month $d_{t}$ fixed effects from the specification (so there are no controls). We again find similar point estimates. However, the standard errors more than double in the fourth row with no controls because fixed effects absorb a large fraction of the variation in outcome variables unrelated to the UI error innovation.

Next we assess the robustness of our results to the assumed process for the UI errors used in extracting the innovations. To account for the sparsity and nonlinearity of the UI error process, our preferred approach imposes a first-order Markov process that generalizes the autoregressive persistence usually imposed on macroeconomic data. In the fifth row, we instead simply first difference the UI error and replace $\epsilon_{s, t}$ in equation (12) with $\Delta \hat{T}_{s, t}=\hat{T}_{s, t}-\hat{T}_{s, t-1}$. In the sixth row, we report the coefficient on the level of $\hat{T}_{s, t}$ but controlling for 12 lags of $\hat{T}_{s, t}$. This specification is conceptually similar to defining the UI error innovation as the structural residual from a vector autoregression in $\hat{T}_{s, t}$ and $u_{s, t}$ with 12 lags and $\hat{T}_{s, t}$ first in a Cholesky ordering. ${ }^{31}$ The limited response of unemployment and vacancies and the significantly positive response of the fraction receiving UI remain robust to these alternative specifications.

Finally, the last two rows of Table IX report instrumental variable-type specifications. ${ }^{32}$ The seventh row shows a control function specification in which we regress outcomes $y_{s, t+h}$ on the change in the observed UI duration $\Delta T_{s, t}^{*}$ controlling for the change in the UI duration $\Delta T_{s, t}$ based on the revised data, the lags of unemployment, state dummies, and monthly dummies. Because we control for changes in UI duration due to fundamentals with $\Delta T_{s, t}$, the remaining variation in $\Delta T_{s, t}^{*}$ reflects changes in UI benefit duration that arise from measurement error only. The eighth row shows an IV specification treating $T_{s, t}^{*}$ as an endogenous variable and using $\epsilon_{s, t}$ as an excluded instrument. ${ }^{33}$

31. Formally, after demeaning with respect to the state and month fixed effects, the specification is a Jordà (2005) local projection based on a bivariate system in $u_{s, t}$ and $\hat{T}_{s, t}$ with 12 lags and $\hat{T}_{s, t}$ being first in the Cholesky ordering. The Cholesky identification assumption is that the forecast error in $\hat{T}_{s, t}$ does not respond to the contemporaneous structural innovation to the unemployment rate. As a justification for the ordering, recall that due to reporting lags UI benefits in month $t$ are only a function of unemployment rates for month $t-1$ and earlier.

32 . We thank two anonymous referees for pointing out the similarity of our approach to these specifications.

33. We discussed the relationship between our baseline OLS specification and the IV specification in Section III.C. The IV specification also provides an 
The effects of unemployment and vacancies remain small and statistically insignificant, whereas the response of the fraction of unemployed receiving UI increases slightly in these specifications relative to the baseline. We cannot reject the null hypothesis that the IV estimates and the OLS estimates are equal at conventional levels of significance.

\section{DMP Model with Benefit Extensions}

Our empirical estimates suggest a small macroeconomic effect of extending benefits. In this section we interpret these results through the lens of a standard DMP model. The model illustrates the basic logic of why benefit extensions might lead to higher unemployment. We use it to assess the sensitivity of our conclusions when workers and firms perceive a UI error to be more transitory than a benefit extension caused by a persistent increase in the unemployment rate and to extensions that persist for longer than a year, as in the aftermath of the Great Recession. In addition, we show that in the model the extension of benefits from 26 to 99 weeks does not introduce a significant degree of nonlinearity, corroborating the results in Section V.B for the stability of the responses of labor market variables to UI errors at different baseline levels of duration.

We augment a standard DMP model with a UI policy. The model shares many features with the models used by HKMM and Mitman and Rabinovich (2014) to argue that benefit extensions cause unemployment to remain persistently high following a negative shock. We reach a different conclusion because our empirical estimates imply a lower level of the opportunity cost of employment in the model than what is assumed by these papers. ${ }^{34} \mathrm{We}$ describe only the elements of the model essential to our argument and provide additional detail in Online Appendix C.

Each period a measure $u_{t}$ of unemployed workers search for jobs and a measure $1-u_{t}$ of employed workers produce output. Unemployed individuals find jobs at a rate $f_{t}$, which is determined in equilibrium. Employed individuals separate from their jobs at an exogenous rate $\delta_{t}$. Employed individuals who lose their jobs

alternative way of addressing the possibility of attenuation bias stemming from measurement error in the revised data.

34. This result echoes Costain and Reiter (2008), who point out that models with a high level of opportunity cost generate stronger effects of policies on labor market outcomes than the effects found in cross-country comparisons. 
become eligible for UI benefits with probability $\gamma$. Unemployed individuals who are eligible for UI and do not find jobs lose their eligibility with probability $e_{t}$. The key policy variable in our model is the (expected) duration of benefits $T_{t}^{*}$, which equals the inverse of the expiration probability, $T_{t}^{*}=\frac{1}{e_{t}}$. Ineligible unemployed who do not find jobs remain ineligible for UI benefits.

Risk-neutral individuals discount the future with a factor $\beta$. Employed individuals consume their wage earnings $w_{t}$. The value of an individual who begins period $t$ as employed is given by $W_{t}$. Ineligible unemployed derive a flow value from nonmarket work equal to $\xi$. The value of an individual who begins period $t$ as ineligible is $U_{t}^{I}$. Eligible unemployed receive an additional UI benefit $B$. The value of an individual who begins period $t$ as eligible is $U_{t}^{E}$. We define the value of the average unemployed individual as $U_{t}=\omega_{t} U_{t}^{E}+\left(1-\omega_{t}\right) U_{t}^{I}$, where $\omega_{t}$ is the fraction of the unemployed who are eligible for and receive UI.

The surplus of employment for the average unemployed is given by the difference between the value of working and the value of unemployment, $S_{t}=W_{t}-U_{t}=w_{t}-z_{t}+\beta\left(1-\delta_{t}-\right.$ $\left.f_{t}\right) \mathbb{E}_{t} S_{t+1}$, where $z_{t}$ denotes the flow opportunity cost of employment for the average unemployed:

$$
z_{t}=\xi+\underbrace{\omega_{t} B-\left(\delta_{t}\left(\gamma-\omega_{t}\right)+\left(1-f_{t}\right) \omega_{t} e_{t}\right) \beta\left(\mathbb{E}_{t} U_{t+1}^{E}-\mathbb{E}_{t} U_{t+1}^{I}\right)}_{b_{t}} .
$$

In equation (16), $\xi$ denotes the flow value of nonmarket work and $b_{t}$ denotes the benefit component of the opportunity cost of employment. This expression nests the corresponding expression for the opportunity cost in the standard DMP model (for instance, Shimer 2005) where $b_{t}=B$ if $e_{t}=0$ and $\gamma=\omega_{t}=1$, that is, when all unemployed individuals receive benefits. More generally, $b_{t}$ is lower than the benefit $B$. The difference occurs because some of the unemployed are not eligible for benefits, and even for those unemployed who are eligible, benefits eventually expire. ${ }^{35}$ Extending benefits, which here means a decline in the expiration probability $e_{t}$, increases the fraction of the unemployed who are eligible, $\omega_{t}$, and raises $b_{t}$ and $z_{t}$.

35. The first effect is captured by the first term of $b_{t}$ which is lower than $B$ when $\omega_{t}<1$. The second effect is captured by the second term which is positive because $\gamma>\omega_{t}$ and $\mathbb{E}_{t} U_{t+1}^{E}>\mathbb{E}_{t} U_{t+1}^{I}$. 
The value of a firm that has matched with a worker is given by $J_{t}=p_{t}-w_{t}+\beta\left(1-\delta_{t}\right) \mathbb{E}_{t} J_{t+1}$, where $p_{t}$ denotes aggregate labor productivity. Free entry drives the expected value of creating a vacancy to zero, giving $\frac{\kappa}{q_{t}}=\beta \mathbb{E}_{t} J_{t+1}$, where $\kappa$ denotes the upfront cost that an entrant pays to create a vacancy and $q_{t}$ denotes the rate at which vacancies are filled. A constant returns to scale matching technology $m_{t}=m_{t}\left(u_{t}, v_{t}\right)$ converts job seekers and vacancies into new matches. Denoting market tightness by $\theta_{t}=\frac{v_{t}}{u_{t}}$, an unemployed individual matches with a firm at rate $f_{t}\left(\theta_{t}\right)=\frac{m_{t}}{u_{t}}$ and firms fill vacancies at rate $q_{t}\left(\theta_{t}\right)=\frac{m_{t}}{v_{t}}=\frac{f_{t}\left(\theta_{t}\right)}{\theta_{t}}$.

Firms and workers split the surplus from an additional match according to the generalized Nash bargaining solution. We denote by $\mu$ the bargaining power of workers. The wage is chosen to maximize the product $S_{t}^{\mu} J_{t}^{1-\mu}$. This leads to a standard wage equation:

$$
w_{t}=\mu p_{t}+(1-\mu) z_{t}+\mu \kappa \theta_{t} .
$$

The duration of UI benefits is given by $T_{t}^{*}=T_{t}+\hat{T}_{t}$, where $T_{t}$ denotes the duration of UI benefits in the absence of any measurement error and $\hat{T}_{t}$ is the UI error. Consistent with the results in Section V.D that agents respond only to the revised unemployment rate, we assume that firms and workers know the underlying fundamentals (for instance, $u_{t}, p_{t}, w_{t}$ ) at the beginning of each period. The statistical agency makes errors in the measurement of the true unemployment rate, which results in UI errors $\hat{T}_{t}$. Thus, agents distinguish in real time between extensions caused by UI errors and extensions caused by true fundamentals.

We now discuss the effects of UI policy in this model. An increase in the current duration of benefits affects equilibrium outcomes to the extent that firms and workers expect it to persist in future periods. Combining the definition of firm's value $J_{t}$ with the free entry condition, the decision to create a vacancy in the current period depends on the expectation of the present discounted value of firm profits:

$$
\frac{\kappa}{q_{t}\left(\theta_{t}\right)}=\mathbb{E}_{t} \sum_{j=1}^{\infty} \beta^{j}\left(\prod_{i=1}^{j} \frac{\left(1-\delta_{t+i-1}\right)}{\left(1-\delta_{t}\right)}\right)\left(p_{t+j}-w_{t+j}\right),
$$

where $q_{t}\left(\theta_{t}\right)$ is a decreasing function of current market tightness $\theta_{t}=\frac{v_{t}}{u_{t}}$. By raising the fraction of unemployed who are eligible for UI, an extension of benefits increases future opportunity costs and 

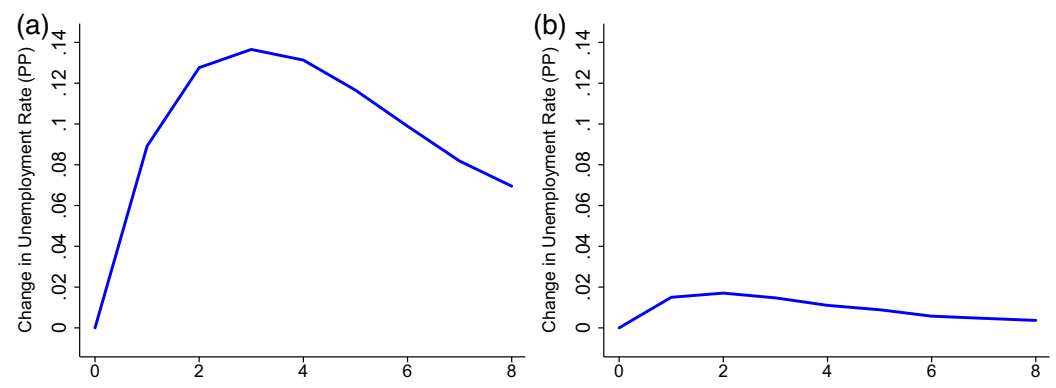

FIGURE VII

Impulse Response of the Unemployment Rate in the Model

The figure plots the coefficients on $\epsilon_{t}$ from the regression $u_{t+h}=\beta(h) \epsilon_{t}+$ $\sum_{j=0}^{11} \gamma_{j}(h) u_{t-j}+v_{t+h}$ using data generated from model simulations. Panel (a) on the left simulates the model parameterized with a "high" $b=0.15$, and panel (b) on the right simulates the model parameterized with a "low" $b=0.06$.

wages as shown in equation (17). Higher wages lower the expected present value of firm profits and decrease firms' willingness to create vacancies. Fewer vacancies make it more difficult for the unemployed to find jobs, increasing the unemployment rate. ${ }^{36}$

We parameterize two versions of the model (see Online Appendix $\mathrm{C}$ for more details). In the "low $b$ " model, we pick $b=0.06$ and $z=\xi+b=0.87$ in the steady state. The value of $b=0.06$ accords with the finding in Chodorow-Reich and Karabarbounis (2016) that benefits make up a small fraction of the average opportunity cost. In the "high $b$ " model, we pick $b=0.15$ and $z=\xi$ $+b=0.96$. The value of $z=0.96$ was chosen by Hagedorn and Manovskii (2008) to target the sensitivity of wages with respect to productivity in the aggregate data.

Figure VII plots the impulse response of the unemployment rate with respect to a one-month UI error innovation using model-simulated data. As described already, an extension of UI benefits reduces firm profits from filling a vacancy. In the high $b$ model, firm profits are very small on average because average match surplus-the difference between the marginal product and the opportunity cost of employment-is

36. In our model, all workers have the same job-finding rate irrespective of UI eligibility, a point we return to in the conclusion. Allowing UI policy to affect worker search intensity in this model would further discourage vacancy creation by reducing the job-filling rate as well as directly increase unemployment by lowering the match rate for a given number of vacancies and unemployed. 

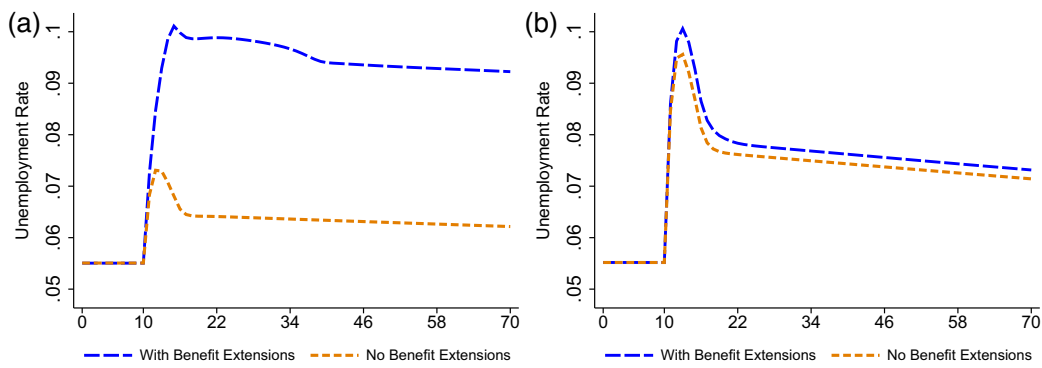

FiguRE VIII

Unemployment Path in the Model

The figure plots the path of unemployment in response to a sequence of negative shocks with and without benefit extensions in the high $b$ (panel a) and the low $b$ model (panel b).

small. Therefore, the extension of benefits lowers firms' willingness to create vacancies substantially. As the left panel of Figure VII shows, the maximal response of the unemployment rate is close to 0.14 percentage point in the high $b$ model. In the low $b$ model depicted in the right panel, the unemployment rate increases by less than 0.02 percentage point. With a low $b$, firm profits are on average higher and the extension of benefits leads to smaller movements in equilibrium vacancies and unemployment.

We next examine the effects of a benefit extension caused by a recession rather than by measurement error. For this experiment, we shut down all UI errors and set $\hat{T}_{t}=0$ for all periods. We start each of the low $b$ and high $b$ economies in a stochastic steady state in which no shock occurs for a large number of periods. Beginning in month 10 , we introduce a sequence of productivity and separation shocks chosen so that unemployment reaches roughly $10 \%$ with benefit extensions turned on. Online Appendix C reports the paths of these shocks.

The left panel of Figure VIII plots the paths of unemployment in the high $b$ model with and without an EB policy. The upper line shows the path when benefit extensions follow a policy rule similar to that in place during the Great Recession, so that the duration of benefits rises from 6 to eventually 20 months. Unemployment peaks at roughly $10 \%$ and remains persistently high. The lower line shows the path of unemployment in an alternative UI policy regime where the duration of benefits always equals 
$T_{t}^{*}=T_{t}=6$ months. Consistent with the conclusions of Mitman and Rabinovich (2014) and HKMM, the difference between the two lines shows the large effect that benefit extensions have on the path of the unemployment rate in the DMP model with a high $b$.

By contrast, the right panel of Figure VIII shows a much smaller effect of benefit extensions on unemployment dynamics. As in the high $b$ model, the duration of benefits increases to 20 months as soon as the unemployment rate exceeds $9 \%$. However, the level of the opportunity cost is small on average, and therefore, this extension does not affect significantly the path of the unemployment rate. The average distance between the two unemployment paths is less than 0.3 percentage point, close to the linear extrapolation in Section V.B. Because only the low $b$ model matches the response of unemployment to a one-month UI error innovation, the results in Figure VIII validate the limited influence of UI extensions in a DMP model with large and persistent benefit extensions.

\section{CONCLUSION}

Identifying the effect of UI benefit extensions on macroeconomic outcomes is challenging because benefits are extended in times of elevated unemployment. This simultaneity happens both because U.S. law makes benefit extensions a function of state economic conditions and because policy makers enact emergency compensation in recessions. We show how to use data revisions to decompose variation in the duration of benefits over time and across states into the part coming from actual differences in economic fundamentals and the part coming from measurement error in the real-time data used to determine benefit extensions. This methodology is potentially applicable to other policy variables that depend on measured economic conditions, other outcome variables, or in different countries. ${ }^{37}$

Using only the measurement error component for identification, we find an economically reasonable increase in the number of individuals receiving UI, but only a limited influence of benefit

37. For example, states with high unemployment rates can receive waivers for the cap on the number of months an able-bodied adult without benefits can receive SNAP benefits (food stamps) in the United States and many countries extend UI benefits based on regional unemployment rates. 
extensions on key state-level macroeconomic outcomes, including unemployment, employment, vacancies, and wages. Our results imply that the unprecedented increase in benefits during the Great Recession contributed at most 0.3 percentage point to the increase in the unemployment rate.

A standard DMP model can rationalize this small response if the opportunity cost of giving up benefits is low for the average unemployed. Other economic channels that may explain the limited influence of benefit extensions we measure in the data include an offsetting stimulus effect from transferring resources to unemployed individuals with high marginal propensity to consume, labor market spillovers as lower search effort by UI recipients raises job-finding rates for nonrecipients, and wage-bargaining protocols that do not depend on the opportunity cost of employment. Quantifying each of these channels separately would be a valuable step for future research. On the other hand, we know of no labor market theory in which UI extensions substantially raise unemployment without requiring a high opportunity cost of giving up benefits and a much larger response of unemployment to a UI error than we measure in the data.

In this article we do not estimate how individual-level outcomes respond to benefit extensions. Recent studies have found mixed effects at the individual level (Rothstein 2011; Farber and Valletta 2015; Johnston and Mas forthcoming). Can one reconcile the small macroeconomic effects we find with those studies that find larger microeconomic effects, such as Johnston and Mas (forthcoming)? Models with job rationing provide one such avenue. In these models, the job-finding rate of UI recipients declines, giving a large microeconomic effect, but the job-finding rate of nonrecipients increases due to the declining competition in the job market. Such displacement effects are consistent with the findings of Crepon et al. (2013) and Lalive, Landais, and Zweimüller (2015) among others.

Finally, the microeconomic function of UI is to provide income replacement for individuals who have lost their jobs. The value of this insurance mechanism may increase in the duration of an unemployment spell as individuals draw down on their assets and other sources of income. The results in this article do not speak to this income support function nor to the microeconomic rationale for increasing insurance during recessions when the typical duration of unemployment spells rises. Our results simply say that UI extensions do not have large negative macroeconomic effects. 


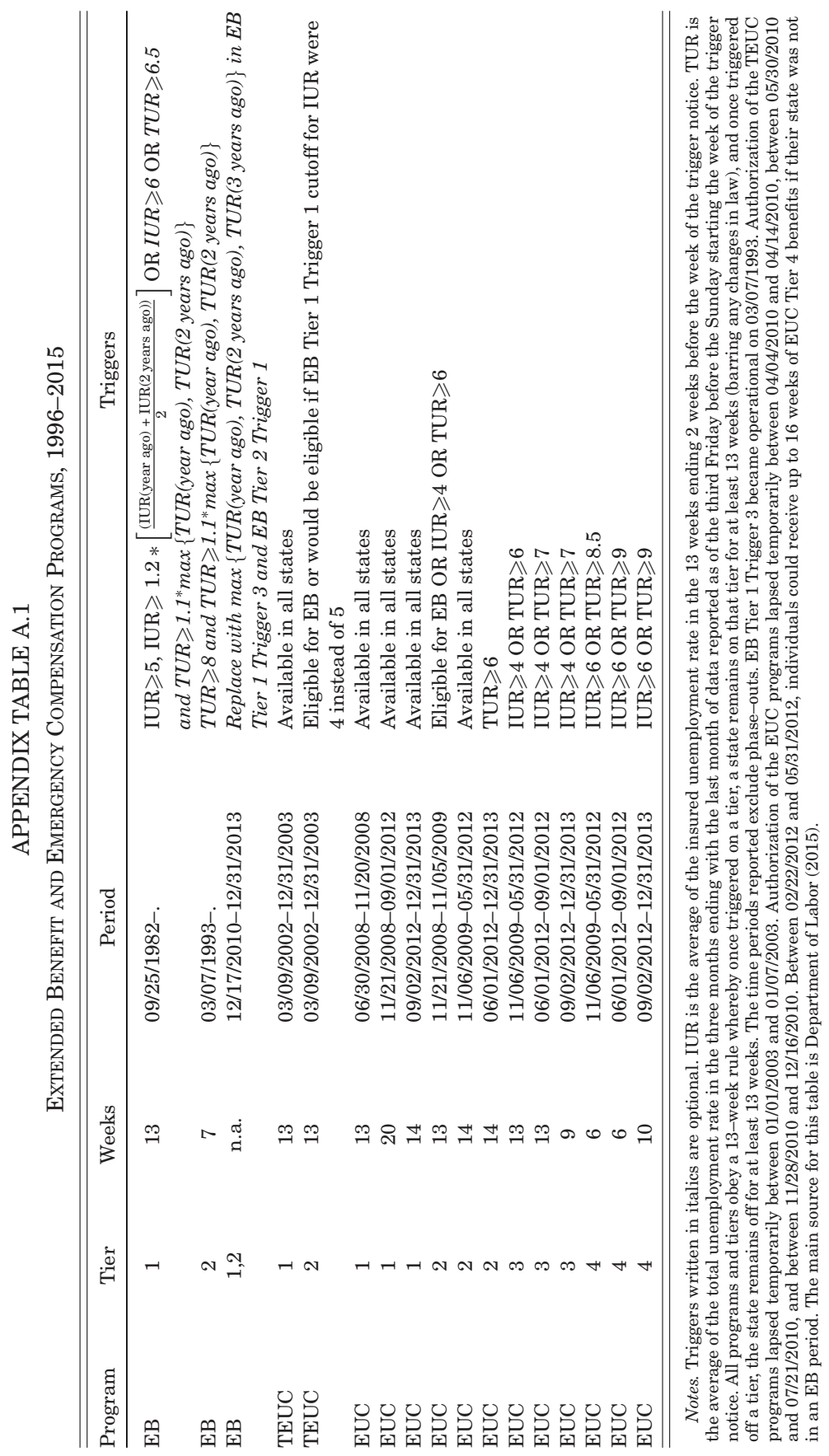




\section{Harvard University and National Bureau of Economic RESEARCH \\ Federal Reserve Board of Governors \\ University of Minnesota, Federal Reserve Bank of Minneapo- Lis, and National Bureau of Economic RESEARCH}

\section{SUPPLEMENTARY MATERIAL}

An Online Appendix for this article can be found at The Quarterly Journal of Economics online. Data and code replicating tables and figures in this article can be found in Chodorow-Reich, Coglianese, and Karabarbounis (2018), in the Harvard Dataverse, doi:10.7910/DVN/DVGSZS.

\section{REFERENCES}

Alvarez, Javier, and Manuel Arellano, "The Time Series and Cross-Section Asymptotics of Dynamic Panel Data Estimators," Econometrica, 71 (2003), 11211159.

Amaral, Pedro, and Jessica Ice, "Reassessing the Effects of Extending Unemployment Insurance Benefits," Federal Reserve Bank of Cleveland, Economic Commentary, 2014.

Baily, Neil, "Some Aspects of Optimal Unemployment Insurance," Journal of Public Economics, 10 (1978), 379-402.

Barro, Robert, "The Folly of Subsidizing Unemployment," Wall Street Journal, August 30, 2010.

Blank, Rebecca, and David Card, "Recent Trends in Insured and Uninsured Unemployment: Is There an Explanation?," Quarterly Journal of Economics, 106 (1991), 1157-1189.

Boone, Christopher, Arindrajit Dube, Lucas Goodman, and Ethan Kaplan, "Unemployment Insurance Generosity and Aggregate Employment," IZA Discussion Paper no. 10439, 2016.

Bureau of Labor Statistics, "Report on Revision to State and Area Time-Series Models," Technical Report, 2014. , "Questions and Answers on the Local Area Unemployment Statistics (LAUS) Program 2015 Redesign,” Technical Report, 2015.

Card, David, Raj Chetty, and Andrea Weber, "Cash-on-Hand and Competing Models of Intertemporal Behavior: New Evidence from the Labor Market," Quarterly Journal of Economics, 122 (2007), 1511-1560.

Card, David, and Phillip B. Levine, "Extended Benefits and the Duration of UI Spells: Evidence from the New Jersey Extended Benefit Program," Journal of Public Economics, 78 (2000), 107-138.

Chetty, Raj, "A General Formula for the Optimal Level of Social Insurance," Journal of Public Economics, 90 (2006), 1879-1901.

Chodorow-Reich, Gabriel, John Coglianese, and Loukas Karabarbounis, "Replication Data for: 'The Macro Effects of Unemployment Benefit Extensions: A Measurement Error Approach'," (2018). Harvard Dataverse, doi:10.7910/DVN/DVGSZS.

Chodorow-Reich, Gabriel, and Loukas Karabarbounis, "The Cyclicality of the Opportunity Cost of Employment," Journal of Political Economy, 124 (2016), $1563-1618$. 
Congressional Budget Office, "Unemployment Insurance in the Wake of the Recent Recession,” Technical Report, 2012.

Costain, James, and Michael Reiter, "Business Cycles, Unemployment Insurance, and the Calibration of Matching Models," Journal of Economic Dynamics and Control, 32 (2008), 1120-1155.

Crepon, Bruno, Esther Duflo, Marc Gurgand, Roland Rathelot, and Philippe Zamora, "Do Labor Market Policies Have Displacement Effects? Evidence from a Clustered Randomized Experiment," Quartely Journal of Economics, 128 (2013), 531-580.

Di Maggio, Marco, and Amir Kermani, "The Importance of Unemployment Insurance as an Automatic Stabilizer," Columbia Business School Research Paper no. $15-31,2015$.

Diamond, Peter, "Wage Determination and Efficiency in Search Equilibrium," Review of Economic Studies, 49 (1982), 217-227.

Dieterle, Steven, Otavio Bartalotti, and Quentin Brummet, "Revisiting the Effects of Unemployment Insurance Extensions on Unemployment: A Measurement Error-Corrected Regression Discontinuity Approach," CARRA Working Paper Series no. 2016-01, 2016.

Farber, Henry, and Robert Valletta, "Do Extended Unemployment Benefits Lengthen Unemployment Spells? Evidence from Recent Cycles in the U.S. Labor Market," Journal of Human Resources, 50 (2015), 873-909.

Ganong, Peter, and Pascal Noel, "Consumer Spending during Unemployment: Positive and Normative Implications," University of Chicago Working Paper, 2017.

Hagedorn, Marcus, Fatih Karahan, Iourii Manovskii, and Kurt Mitman. "Unemployment Benefits and Unemployment in the Great Recession: The Role of Macro Effects," NBER Working Paper no. 19499, 2015.

Hagedorn, Marcus, and Iourii Manovskii, "The Cyclical Behavior of Equilibrium Unemployment and Vacancies Revisited," American Economic Review, 98 (2008), 1692-1706.

Hagedorn, Marcus, Iourii Manovskii, and Kurt Mitman, "The Impact of Unemployment Benefit Extensions on Employment: The 2014 Employment Miracle?," NBER Working Paper No. 20884, 2015.

Hall, Robert, "Some Observations on Hagedorn, Karahan, Manovskii, and Mitman," Stanford University Working Paper, 2013.

Hansen, Gary, and Ayse Imrohoroglu, "The Role of Unemployment Insurance in an Economy with Liquidity Constraints and Moral Hazard," Journal of Political Economy, 100 (1992), 118-142.

Johnston, Andrew, and Alexandre Mas, "Potential Unemployment Insurance Duration and Labor Supply: The Individual and Market-level Response to a Benefit Cut," Journal of Political Economy, forthcoming.

Jordà, Òscar, "Estimation and Inference of Impulse Responses by Local Projections," American Economic Review, 95 (2005), 161-182.

Kekre, Rohan, "Unemployment Insurance in Macroeconomic Stabilization," Harvard University Working Paper, 2016.

Kroft, Kory, and Matthew Notowidigdo, "Should Unemployment Insurance Vary with the Unemployment Rate? Theory and Evidence," Review of Economic Studies, 3 (2016), 1092-1124.

Krueger, Alan, and Bruce Meyer, "Labor Supply Effects of Social Insurance," Handbook of Public Economics, Alan Auerbach and Martin Feldstein, eds. (Amsterdam: Elsevier, 2002), 2327-2392.

Krusell, Per, Toshihiko Mukoyama, and Aysegul Sahin, "Labour-Market Matching with Precautionary Savings and Aggregate Fluctuations," Review of Economic Studies, 77 (2010), 1477-1507.

Lalive, Rafael, Camille Landais, and Josef Zweimüller, "Market Externalities of Large Unemployment Insurance Extension Programs," American Economic Review, 105 (2015), 3564-3596. 
Landais, Camille, Pascal Michaillat, and Emmanuel Saez, "A Macroeconomic Approach to Optimal Unemployment Insurance: Theory," American Economic Journal: Economic Policy, 2 (2018), 152-181.

Levine, Phillip B., "Spillover Effects between the Insured and Uninsured Unemployed," Industrial and Labor Relations Review, 47 (1993), 73-86.

Marinescu, Ioanna, "The General Equilibrium Impacts of Unemployment Insurance: Evidence from a Large Online Job Board," Journal of Public Economics, 150 (2017), 14-29.

Mitman, Kurt, and Stanislav Rabinovich, "Do Unemployment Benefit Extensions Explain the Emergence of Jobless Recoveries?," Stockholm University Working Paper, 2014.

Mortensen, Dale, and Christopher Pissarides, "Job Creation and Job Destruction in the Theory of Unemployment," Review of Economic Studies, 61 (1994), 397415.

Nakajima, Makoto, "A Quantitative Analysis of Unemployment Benefit Extensions," Journal of Monetary Economics, 59 (2012), 686-702.

Ramey, Valerie, "Macroeconomic Shocks and Their Propagation," Handbook of Macroeconomics, 2 (2016), 71-162.

Romer, Christina D., and David H. Romer, "Does Monetary Policy Matter? A New Test in the Spirit of Friedman and Schwartz," In NBER Macroeconomics Annual, Olivier Jean Blanchard and Stanley Fischer, eds. (Cambridge, MA: MIT Press, 1989), 121-184.

Rothstein, Jesse, "Unemployment Insurance and Job Search in the Great Recession," Brookings Papers on Economic Activity, (2011) 143-214.

Sahin, Aysegül, Joseph Song, Giorgio Topa, and Giovanni L. Violante, "Mismatch Unemployment," American Economic Review, 104 (2014), 3529-3564.

Schmieder, Johannes, Till von Wachter, and Stefan Bender, "The Effects of Extended Unemployment Insurance Over the Business Cycle: Evidence from Regression Discontinuity Estimates over Twenty Years," Quarterly Journal of Economics, 127 (2012), 701-752.

Shimer, Robert, "The Cyclical Behavior of Equilibrium Unemployment and Vacancies," American Economic Review, 95 (2005), 25-49.

Stock, James, and Mark Watson, "Identification and Estimation of Dynamic Causal Effects in Macroeconomics," Economic Journal, forthcoming.

Summers, Lawrence, "The Economic Case for Extending Unemployment Insurance," White House Blog, July 14, 2010, https://obamawhitehouse.archives. gov/blog/2010/07/14/economic-case-extending-unemployment-insurance. 